Portland State University

PDXScholar

Winter 3-25-2015

\title{
Impact of a Psychology of Masculinities Course on Women's Attitudes toward Male Gender Roles
}

Sylvia Marie Ferguson Kidder

Portland State University

Follow this and additional works at: https://pdxscholar.library.pdx.edu/open_access_etds

Part of the Feminist, Gender, and Sexuality Studies Commons, and the Gender and Sexuality Commons

Let us know how access to this document benefits you.

\section{Recommended Citation}

Kidder, Sylvia Marie Ferguson, "Impact of a Psychology of Masculinities Course on Women's Attitudes toward Male Gender Roles" (2015). Dissertations and Theses. Paper 2210.

https://doi.org/10.15760/etd.2207

This Thesis is brought to you for free and open access. It has been accepted for inclusion in Dissertations and Theses by an authorized administrator of PDXScholar. Please contact us if we can make this document more accessible: pdxscholar@pdx.edu. 
Impact of a Psychology of Masculinities Course on Women's Attitudes toward Male Gender Roles

by

Sylvia Marie Ferguson Kidder

A thesis submitted in partial fulfillment of the requirements for the degree of

\author{
Master of Science \\ in \\ Psychology
}

Thesis Committee:

Eric Mankowski, Chair

Kerth O'Brien

Kimberly Kahn

Portland State University

2015 
(C) 2015 Sylvia Marie Ferguson Kidder 


\begin{abstract}
Individuals are involved in an ongoing construction of gender ideology from two opposite but intertwined directions: they experience pressure to follow gender role norms, and they also participate in the social construction of these norms. An individual's appraisal, positive or negative, of gender roles is called a "gender role attitude." These lie on a continuum from traditional to progressive. Traditional gender role attitudes have been linked to primarily negative outcomes.

This thesis examines attitudes toward — and beliefs about—male gender in women completing an elective course on the psychology of men and masculinities. Study 1 assessed how these students" $(N=32)$ narrative definitions of "man" and "masculinity" changed from the beginning to the end of the class. While there was a significant decrease in the presence of the male role norms of achievement/status and aggression over time, there were no differences in the number of references to men's avoidance of femininity, homophobia, non-relational attitudes toward sex, restrictive emotionality, or self-reliance. Because the coding scheme only measured presence of these male role norms rather than framing or valence, additional characteristics of students' responses are discussed. Study 1 also compared women's $(N=20)$ pre- and post-class male role norm attitudes. Endorsement of global male role norms, aggression, self-reliance, and a composite of particular other male role norms (i.e., "Factor 1" of the Male Role Norms Inventory) were all significantly lower at the end of the class than at the beginning.
\end{abstract} Study 2 examined potential selection effects in the male role attitudes of women choosing to complete the psychology of men and masculinities course $(n=20)$ by 
comparing them to those of women in a psychology research methods course required for the academic major $(n=19)$. It was determined that pre-class male role attitudes did not differ significantly between the two classes. However, small sample sizes severely limited the statistical power to detect such a difference, and other possible explanations for the lack of difference are considered.

Study 3 explored the relationship between women's gender role stress (GRS), which describes stress from coping with restrictive feminine expectations, and attitudes toward male gender roles $(N=32)$. Results showed that women's GRS did not significantly correlate with overall male role attitudes or with specific subcomponents of these role norms (i.e., self-reliance, aggression, and Factor 1). Thus, there was no evidence that gender role pressures experienced by women relate to their gender expectations for men.

While many studies have examined change in attitudes toward women's gender roles, particularly in the context of women's and gender studies courses, there is a lack of research on women's attitudes toward men's roles and the impact on those attitudes of gender coursework focused on masculinity. This research is the first to provide evidence regarding: 1) changes in women's attitudes toward male role norms, and 2) changes in gender role attitudes among students taking a course on the psychology of men and masculinities. Because both men's and women's attitudes toward male role norms are linked to a number of measures of well-being, this research suggests gender-focused education as a potential strategy for improving students' health and relationship quality. 


\section{Dedication}

In loving memory of my father, who inspired my passion for learning and made sure I never wanted for books. 


\section{Acknowledgements}

Ultimately, this thesis owes its completion to my adviser and committee chair, Dr. Eric Mankowski. He challenged me to think in new ways, and I have learned so much from the process of writing this. Moreover, his research continues to inspire me.

I am also very grateful for the support of my committee members, Dr. Kerth O’Brien and Dr. Kimberly Kahn. Their insights and knowledge rounded out this project.

Two research assistants deserve credit for their work coding the qualitative data: Aunna Morkert and Cam Tu Tran. I know they will both go far in whatever careers they choose.

Lastly, many thanks to my patient husband, Samuel Kidder, who was my cheerleader through many long nights and minor crises. I couldn't have done it without you. 


\section{Table of Contents}

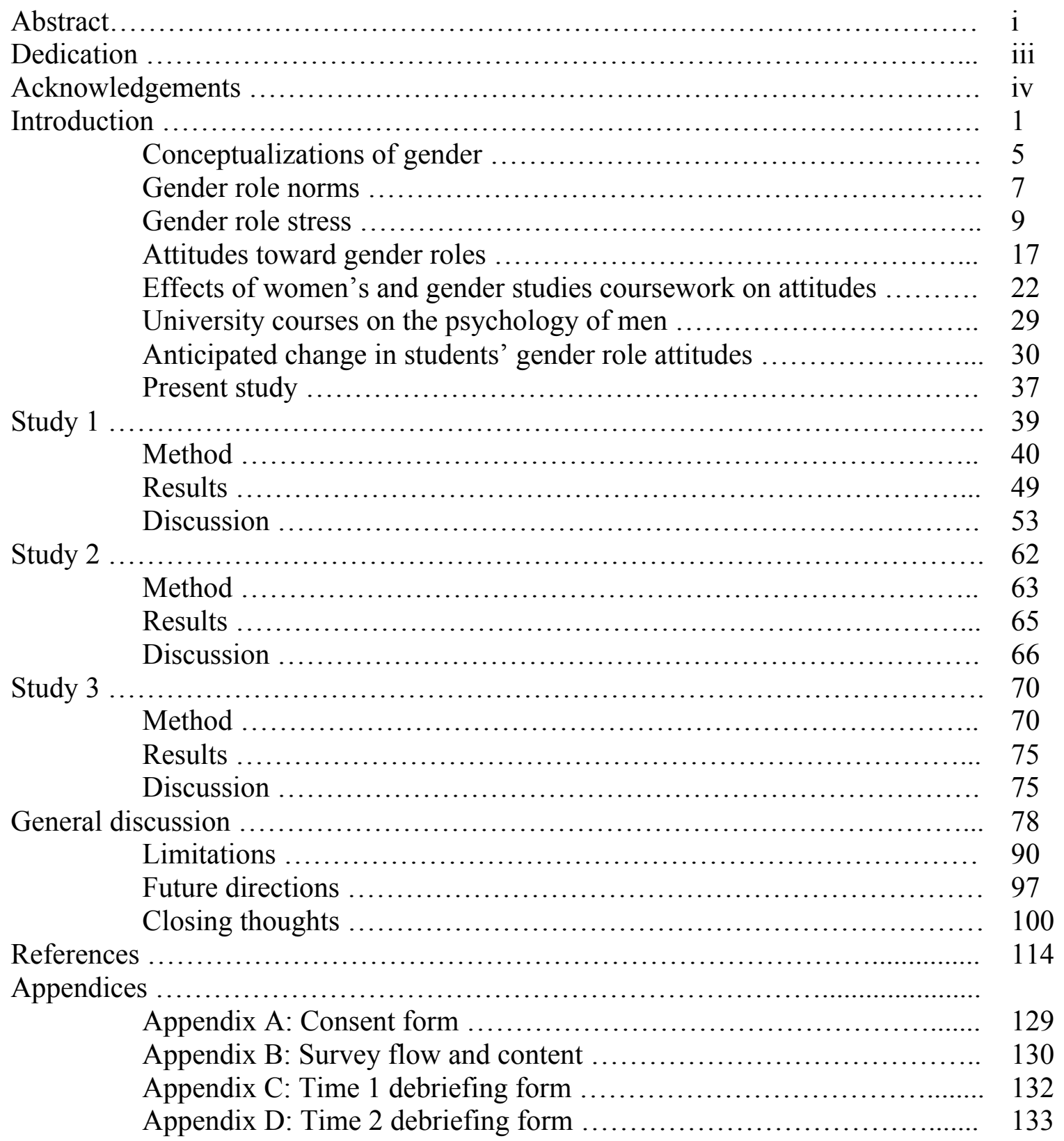




\section{List of Tables}

Table 1: Samples used to test study hypotheses ........................... 102

Table 2: Coding scheme for open-ended responses ........................... 103

Table 3: Internal consistency (Cronbach's alpha) of the MRNI and FGRS ..... 105

Table 4: Hypothesis 1a: $t$-tests comparing pre- and post-class MRNI scores .... 106

Table 5: Hypothesis 1b: Presence of MRNI dimensions in qualitative responses from Psychology of Men and Masculinities students ................. 107

Table 6: Hypothesis 2: $t$-tests comparing MRNI scores across classes .......... 108

Table 7: Hypothesis 3: Correlation of the FGRS and MRNI ....................... 109 


\section{List of Figures}

Figure 1: Change in male role norm endorsement in the Psychology of Men and Masculinities class

Figure 2: Pre-class mean endorsement of male role norms in the Men and Masculinities class compared to the Research Methods class

Figure 3: Percent of responses to "What is a man/masculinity?" referencing male role norms of the MRNI

Figure 4: Number of male role norms referenced in open-ended responses to "What is a man/masculinity?" ..................................... 


\section{Introduction}

Gendered characteristics and roles are commonly perceived as innate and immutable facts of human existence. This phenomenon is evidenced by the interchangeability of the terms "sex" and "gender" in the vernacular. Sex, which distinguishes between females and males of any species, is biologically based and challenging to alter even among those who desire it. While differences between the sexes certainly exist, many of the most visible differences between the sexes, such as appearance and demeanor, are more accurately characterized as gender differences. Gender describes "the behaviors and attitudes that relate to (but are not entirely congruent with) biological sex" (Brannon, 2011). In other words, gender is a social creation, and thus it may vary across time, culture, and social context.

As a social creation, gender exists within and between people. People learn the meaning of gender through their culture while simultaneously forming an identity based on this understanding (Wood \& Eagly, 2012). As a part of identity, gender provides a context for all thoughts and experiences, influencing our behavior, interpretations of ourselves, and perceptions of others (Deaux \& Major, 1987). The social "performance" of gender is an idea popularized by Judith Butler in her 1990 book Gender Trouble. She argued that gender traits and role norms are selfperpetuating and largely arbitrary in origin. In other words, they are socially determined rather than biologically pre-determined. When people act in accordance with the culturally agreed-upon conception of their gender, the resulting performance in turn contributes to the apparent validity of fundamental gender differences. 
The ongoing internalization and performance of gender exerts small influences on individuals' opportunities and experiences that eventually lead to large differences in important life outcomes. Gender role beliefs and expression are linked to differential outcomes in regards to mental health and substance use (e.g., Barrett \& White, 2002; DiDonato \& Berenbaum, 2011; Kazmierczak, 2010; O’Neil, 2008; Rice, Fallon, \& Bamblin, 2011; Sanchez-Lopez, Cuellar-Flores, \& Dresch, 2012; Vandello \& Bosson, 2013), physical health (e.g., Sanchez-Lopez et al., 2012), interpersonal behavior (e.g., Burn \& Ward, 2005; Cohn \& Zeichner, 2006; Kazmierczak, 2010; O’Neil, 2008), and life choices (e.g., Vandello \& Bosson, 2013). Because gender expectations are qualitatively different for women and men, following gender norms may dissimilarly impact outcomes. Masculinity and femininity are not opposites; thus, they are not necessarily associated with divergent outcomes. This principle is illustrated by the tendency for unrealistic body ideals, which exist for both genders, to produce different problems in men and women. Whereas men commonly pursue increased muscularity to fulfill masculine ideals (McCreary, Saucier, \& Courtenay, 2005), women feel substantial social pressure to reduce their weight (Forbes, AdamsCurtis, Rade, \& Jaberg, 2001). When taken to the extreme, both types of behavior can result in serious health consequences.

Thanks in a large part to second and third-wave feminism, the negative impacts of traditional female role norms are now widely recognized. Mainstream American media seems to devote increasing attention to the challenges modern women face in balancing career and family life, striving to maintain strict control over their body and 
appearance, and dealing with the threat of violence. While these are undoubtedly important issues, and it is deeply encouraging that American society is slowly gaining consciousness of the limitations and harms of traditional expectations for women, we must simultaneously deconstruct traditional masculinity. Men, too, suffer the consequences of restrictive gender role norms. However, too often the popular discourse reflects, which simultaneously reinforces, masculine norms. Fewer people seem motivated to challenge traditional masculinity than femininity. Perhaps this is because critical analyses of masculinity are relatively new compared to those of femininity. While many contemporary feminists are also aware of men's issues, feminism was obviously established with a focus on women. Or, perhaps this reluctance stems from an implicit desire to uphold the power dynamic of the patriarchy. Regardless, the plights of these two genders (among others) are complementary rather than contradictory. While the expectations are different, the negative consequences of both sets of expectations have been well documented. The complete effects of gender role expectations are unknown. Past research has linked them to such outcomes as psychopathology (e.g., Bekker \& Boselie, 2002; Gillespie \& Eisler, 1992; Kazmierczak, 2010; Shepard, 2002), interpersonal problems (e.g., Blazina \& Watkins, 2000; Cohn \& Zeichner, 2006; Mahalik et al., 2001; Moore \& Stuart, 2005), and positive attitudes toward particular harmful behaviors (e.g., Glomb \& Espelage, 2005; Kassing, Beesley, \& Frey, 2005; Wade \& Brittan-Powell, 2001). In contrast, past theoretical work and empirical research (some of which are discussed 
throughout this paper) have shown that progressive gender role attitudes can benefit both men and women.

As elaborated upon later, undergraduate classes focusing on gender are one form of intervention that has been consistently shown to impact gender role attitudes (e.g., Stake \& Rose, 1994; Stake et al., 1994). While the research on gender coursework is robust, these studies tend to examine classes geared specifically toward women and women's issues (e.g., Women's Studies, Psychology of Women).

Far less work has been conducted to evaluate the impact of participation in gender classes centered on men and masculinity. Undergraduate coursework on masculinities, which is one possible avenue for changing attitudes toward male role norms, is the focus of this study. Of course, the specialized nature of these courses, and the fact that they are generally offered as electives, means that students enrolling in them are likely to have an existing interest in the topic. Thus, selection effects that result from systematic differences between people who choose and do not choose to take the course are one of the potential explanations of observed changes in attitudes among students in elective courses. Selection effects also must be considered when determining the potential generalizability of changes within individuals in a single group, non-experimental research design. For this study, selection effects are examined by comparing baseline scores among students in both elective and nonelective courses. This facilitates a more accurate interpretation of possible changes in male gender role attitudes from the beginning to the end of an elective class on the psychology of men and masculinities. 


\section{Conceptualizations of gender}

Psychological research supports the hypotheses that cultural understandings of gender are not static and that American conceptualizations have changed rapidly over the last century. Research has found evidence of cohort effects on gender role attitudes in the United States (Brooks \& Bolzendahl, 2004), suggesting that successive generations experience contexts that foster more egalitarian gender role attitudes than those held by the previous generation. Additionally, ideologies about rights (such as civil liberties and sexual tolerance) indirectly influence views on gender through their differential adoption by new cohorts (Brooks \& Bolzendahl, 2004). However, as discussed in further detail later, social contexts such as gender-focused college courses can also impact individuals' gender attitudes within a relatively short period of time.

It is important to understand historic theoretical perspectives of gender because they linger in the popular imagination and continue to influence people's perceptions of themselves and others. One of the earliest views of gender was a binary model, in which there were only two sexes: male and female. This perspective is exemplified by Sigmund Freud's theory of psychosexual development (1905). Gender and sex are not only confounded but also assumed to be intimately related to sexuality. Implicit in his theories are the complete separation of the masculine and the feminine. Sexual desire is described as masculine, and a sexual partner is literally the "object" of desire, echoing the traditional conceptualization of women's sexuality as passive. The idea of masculine sexuality, specifically heterosexuality, as an innate and nearly irrepressible force remains today. Within Freud's framework, children are believed to develop 
gendered characteristics by mimicking their same-sex parent in competition for the attention of their opposite-sex parent; alternatively, spending too much time with individuals of one's own sex was believed to cause homosexuality or bisexuality (1905). Thus, the dichotomous nature of gender was both self-perpetuating and instrumental in the normal development of sexuality.

From this foundation grew the gender identity model, originally named the “sex role identity model," which maintained a psychodynamic perspective. According to Pleck's (1981) later critique of the model, it valued the development of a gender role identity congruent with one's biological sex as essential for psychological wellbeing. Issues of identification were believed to cause negative outcomes ranging from behavioral problems to homosexuality, which was classified as a mental illness (Pleck, 1981). Gender identity was also believed to be malleable in childhood. Thus, interference with the acquisition of appropriately sex-typed behavior, such as femaledominated environments which could encourage feminine traits in boys, was condemned. As in earlier models, there were believed to be exactly two natural, and usually opposing, genders.

In the 1970s, Sandra Bem introduced Bem Sex Role Inventory, which problematized the view of masculinity and femininity as opposing ends of the same spectrum (Bem, 1974). Her model of gender took an innovative approach by conceptualizing masculinity and femininity as separate, intersecting continuums. Thus, psychological androgyny was redefined from being neither very masculine nor feminine, or at the midpoint of the single gender continuum, to being high in both 
masculine and feminine traits. The dimensional model also included the new possibility of being undifferentiated, which described being low in both masculine and feminine characteristics. The existence of a multidirectional spectrum of gendered characteristics has since gained endorsement and become more measurable (e.g., Davidson, 2007; Factor \& Rothblum, 2008; Siebler, 2012). Wider recognition of the variation of possible genders is reflected in terms such as cisgender (a person whose biological sex matches their gender identity) and genderqueer (a person who identifies as neither male nor female), which are slowly beginning to enter the vernacular. However, the popular discourse surrounding gender still tends to characterize it as bipolar or even binary.

\section{Gender role norms}

Within the gender binary, gender role norms dictate how people should act. Gender role norms thus describe the different patterns of behavior expected of women and men. Domains in which these divisions are immediately apparent include career paths, the distribution of household labor and childrearing duties, and expectations for appearance.

Joseph Pleck's (1981) model of sex role strain was a response to both the gender identity and androgyny frameworks of gender. It problematized the assumption that a gender-congruent identity is necessarily positive, and it has provided the foundation for a model examining the measurable negative impacts of gender role expectations (Pleck, 1981). Sex role strain and its relationship with attitudes toward the gender roles of the other sex is one of the focuses of this research study. 
The sex role strain paradigm describes how sex roles are defined based on sex stereotypes and norms; how sex roles are contradictory, inconsistent, and sometimes psychologically dysfunctional, such as aggression in men; and the consequences of violating sex roles (Pleck, 1981). Violating gender norms is described as gender nonconformity/incongruency, whereas gender conformity/congruency is the state of being or behaving in a manner consistent with the expectations for one's gender. Pleck (1981) proposed that while few people completely conform to their gender's prescribed roles, violating norms has negative social and psychological consequences that often cause people to over-conform.

Pleck's (1981) theories about following gender roles have been largely supported by the scientific literature. Many people base their gendered behavior on the reactions they expect to get from others (Good \& Sanchez, 2010). They have good reason for doing so; violating stereotypes is a social transgression that can lead to negative social and economic consequences (Rudman, 1998; Rudman \& Fairchild, 2004). The term backlash effect describes this phenomenon (Rudman, 1998). By inhibiting and marginalizing gender-incongruent actors, the backlash effect also reinforces the apparent validity of gender stereotypes (Rudman \& Fairchild, 2004). There could be many possible motivations for engaging in backlash behavior ranging from those as broad as perceived threat to one's gender ideology to those as specific as maintaining one's own status, but it stands to reason that backlash behaviors would be facilitated by holding traditional gender role attitudes. In other words, endorsement of traditional gender role attitudes could lead people to harm others psychologically, 
materially (e.g., denying a leadership position to an agentic woman), or otherwise through the enforcement of role norms.

Not only are there sanctions for deviating from gender norms, but there can also be benefits to conformity. Research suggests that many people, depending on their motivations and gender values, do in fact experience short-term rewards for conforming to gender expectations. Among college students who value gender normative traits within themselves (i.e., communality for women and dominance for men), responding to situations in gender-congruent ways leads to immediate positive affect and a boost in self-esteem (Witt \& Wood, 2010; Wood, Christensen, Hebl, \& Rothberger, 1997). From a motivational perspective, people to whom embodying the ideal man or woman is important are likely to be motivated to conform to gender norms by extrinsic factors (Good \& Sanchez, 2010). This extrinsic motivation is itself related to lower self-esteem. Thus, the type of motivation, and not gender ideals per se, influences self-esteem; gender conformity is reinforced through positive affect only in those people concerned with external expectations (Good \& Sanchez, 2010).

\section{Gender role stress}

As described by the sex role strain model, expectations and attempts to conform to gender expectations have negative outcomes. Causes and outcomes vary by gender and can be physical or psychological (O’Neil, 2008). Examples include a woman restricting her caloric intake because she worries she is not skinny enough or a man stopping himself from crying to avoid appearing weak. The pattern of negative outcomes resulting from sex role strain in men is referred to as gender role conflict 
(GRC). As "the psychological state in which socialized gender roles have negative consequences for the person or others," gender role conflict is manifested in four different ways: self-directed, expressed toward others, from others to the self, or caused by gender role transitions such as entering puberty or becoming a parent (O’Neil, 2008, p. 362).

Interestingly, there is no measure for gender role conflict in women. The most closely related concept is gender role stress (GRS), which describes stress from coping with restrictive feminine stereotypes. Whereas GRC incorporates external outcomes such as interference with family life resulting from excessive dedication to work, GRS focuses only on internal outcomes such as fear and anxiety. Both, however, include self-directed and other-to-self aspects. Importantly, all measures of GRC and GRS in men and women rely on self-report. One could argue that because men's assessment of the external manifestations of gender role conflict (e.g., the degree to which a focus on work negatively impacts home life) is subjective, in a practical sense it is not very different than women's gender role stress. GRS is measured based on the subjective stress a hypothetical situation would be expected to cause. While the Gender Role Conflict Scale (O’Neil et al., 1986) does not refer explicitly to stress, it primarily consists of items that would necessarily relate to stress, for example, social discomfort (e.g., "Being very personal with other men makes me feel uncomfortable") or pressure from goals or expectations (e.g., "I worry about failing and how it affects my doing well as a man"). In other words, from this perspective, stress is only experienced in response to events perceived to be stressful. 
While gender role conflict and gender role stress are not identical concepts, and are not a direct measure of the social expectations faced by a given individual, they both tap into negative consequences of restrictive gender role expectations. Men's gender role conflict, while not the focus of the present study, is nevertheless important to understand because it is closely tied to women's gender role stress on a conceptual level. Additionally, the body of research on GRC is both deeper and broader than that on GRS. While qualitative differences between gender role expectations make it unreasonable to assume that the relationships found between GRC and other variables would similarly exist with GRS, the research on GRC points to the relevance of gender role strain in varied domains.

The Gender Role Conflict Scale (GRCS), designed to measure the degree to which a male individual is experiencing gender role conflict, focuses on GRC within the respondent and between the respondent and others (O’Neil, 2008). It is theorized that this conflict is comprised of four different dysfunctional components of masculine ideology: the need for success, power, and competition; restrictive emotionality; restrictive affectionate behavior between men; and conflicts between work and family relationships (O’Neil et al., 1986). This factor structure has been validated in nonclinical samples of male students (O’Neil et al., 1986), students receiving counseling (Good et al., 1995), men of color (Wester, 2008), and lesbian women and gay men (Herdman, Choi, Fuqua, \& Newman, 2012), among others (O’Neil, 2008). Unsurprisingly, these factors are similar to those of a measure of attitudes toward male role norms, the Male Role Norms Inventory (MRNI; Levant et al., 1992). The scope 
of the MRNI extends beyond that of the GRCS but includes the similar constructs of self-reliance, aggression, achievement/status, and restrictive emotionality. One dimension of the MRNI, fear and hatred toward homosexuals, is also referred to as "homophobia." The MRNI is discussed in greater detail later in this paper, but for now it is important to simply note the similarities between the MRNI and the GRCS.

Unlike attitudes toward women's roles, there is very little research on change in attitudes toward men's roles. However, the similarities between the MRNI and GRCS suggest that the GRCS's assessment of the pressures experienced by men would give it some utility as a proxy for others' gender role attitudes. In support of this idea, the GRCS has been shown to relate to gender role attitudes within men.

Firstly, gender role conflict predicts men's attitudes toward other men. Given the early and enduring concept of the male gender as incompatible with homosexuality, as in the gender identity model, it is unsurprising that gender role conflict positively relates to homophobic attitudes (Kilianski, 2003; Walker, Tokar, \& Fischer, 2000). Another study found that gender role conflict is related to male antigay attitudes through men's fear of appearing feminine, possibly because of a mental association between male homosexuality and femininity (Wilkinson, 2004).

Secondly, gender role conflict predicts men's attitudes toward women's roles. All subscales of the GRCS have been shown to negatively correlate with progressive attitudes toward women's roles, and this relationship is particularly dramatic for the Restrictive Affectionate Behavior Toward Men subscale (Robinson \& Schwartz, 2004). While it is unclear why this subscale is an especially strong predictor, men 
high in this dimension also tend to exhibit increased homophobia, suggesting that they are threatened by feminine characteristics in general.

In addition to its relationship with gender role attitudes, gender role conflict has been shown to predict a variety of negative intrapersonal and interpersonal outcomes. Not only is it correlated with the relatively common problems of depressive symptoms (Shepard, 2002), anxiety (Blazina \& Watkins, 1996; Hayes \& Mahalik, 2000), and negative self-esteem (Mahalik, Locke, Theodore, Cournoyer, \& Lloyd, 2001), but it is also associated with anger and substance use (Blazina \& Watkins, 1996), the inability to describe one's own emotions (Berger, Levant, McMillan, Kelleher, \& Sellers, 2005), and an increased likelihood of suicide (Houle, Mishara, \& Chagnon, 2008). In one study, men's scores on the GRCS explained 50\% of the variability between those who did and did not attempt suicide, even after controlling for income and the presence of mental illness in the past year (Houle et al., 2008).

Negative interpersonal problems include increased aggression (Cohn \& Zeichner, 2006); attachment, separation, and intimacy problems (Blazina \& Watkins, 2000; Mahalik et al., 2001); and marital dissatisfaction (Campbell \& Snow, 1992). The links between GRC and the domains of interpersonal and sexual violence are especially alarming. High GRC is a risk factor for the perpetration of intimate partner violence (Moore \& Stuart, 2005; Schwartz, Waldo, \& Daniel, 2005), sexual aggression (Rando, Rogers, \& Brittan-Powell, 1998), and positive attitudes toward sexual harassment (Glomb \& Espelage, 2005). One study of men in a domestic 
violence treatment program found that elements of GRC explained $14 \%$ of the variability in physical abuse perpetration and $21 \%$ of the variability in isolating one's intimate partner (Schwartz et al., 2005). In another study, GRC relating to success, power, and competition also explained $35 \%$ of the variance in men's acceptance of rape myths (Kassing et al., 2005). Thus, substantial evidence supports the assertion that gender role conflict, a kind of gender role strain, has serious impacts on interpersonal and behavioral outcomes.

As would be expected given O'Neil's (2008) theory regarding role transitions, GRC appears to vary based on age or stage of life; college-age men suffer from higher conflict in the area of success, power, and competition as compared to middle-aged men, who have relatively greater conflict between work and family (Cournoyer \& Mahalik, 1995). This same pattern of differences has been found in a sample of Australian college- and middle-aged men (Theodore \& Lloyd, 2000). These results suggest that expectations of men are changing through their lifespan. For example, the common life transitions from college (and presumably academic competition) to career would parallel the changes in stress observed in different domains.

Women's gender stress appears to be qualitatively distinct from men's gender role conflict and stress. The sources of women's gender role stress are based on female gender role ideals (e.g., nurturance, passivity) rather than the male role ideals (e.g., dominance, success, stoicism). The Feminine Gender Role Stress Scale (FGRS; Gillespie \& Eisler, 1992) was developed with undergraduate student samples to assess women's individual responses to gender role stressors. Items ask participants to rate 
the stressfulness of different hypothetical situations (e.g., "being considered promiscuous"; "finding out that you gained 10 pounds"). Factor analysis indicated that stress was caused by five main fears: unemotional relationships, physical unattractiveness, victimization, behaving assertively, and not being nurturant. Fear of victimization can be seen as an internalization of helplessness, another "feminine" characteristic. All of these stressors, save victimization, reflect qualities Western society values or expects in a woman: emotional connectivity, beauty, passivity, and nurturing tendencies. Interestingly, women's FGRS scores do not correlate significantly with their scores of expressed femininity (assessed using the Personal Attributes Questionnaire; Gillespie \& Eisler, 1992). Thus, gender role stress is distinct from the embodiment of gender role ideals; rather, it is the perceived failure to achieve these ideals.

Feminine gender role stress has been linked to several different types of disorders. Not only has FGRS been found to correlate positively with depressive symptoms, explaining around $10 \%$ of the variance in depression symptoms in one study (Gillespie \& Eisler, 1992), but a study of GRS in Polish women also found that those high in GRS (based on a median-split) were between .4 and .8 standard deviations above the mean on non-pathological symptoms of borderline, histrionic, narcissistic, avoidant, and dependent personality disorders than women with low GRS (Kazmierczak, 2010).

Given the societal expectation of thinness within women, it is unsurprising that FGRS also relates to eating disorders (Bekker \& Boselie, 2002). Indeed, most of the 
literature on FGRS has examined its relationship to eating and body image, perhaps because of the particular salience of physical ideals for women. One study discovered that female inpatients with eating disorders, compared to those with other kinds of psychiatric disorders, suffer from more gender role stress (Martz, Handley, \& Eisler, 1995). Another study found that—-mediated by body dissatisfaction and overcontrol - the fear of unattractiveness subscale of the FGRS relates to dietary restraint, eating concern, and bingeing/purging, whereas the fear of assertiveness subscale predicts eating concern (Mussap, 2007). GRS also has a relationship with a different body-perception issue: somatic symptoms. GRS, but not femininity, predicted somatic symptoms (i.e., unexplained physical problems such as dizziness, stomach pain, blurred vision) in a sample of female undergraduate students (Perry, 2010). Thus, GRS, like GRC, correlates with a variety of negative outcomes. However, perhaps because of its origins in the counseling psychology literature and relatively recent measurability, the research on the role of GRS lacks the breadth of research on men's gender role conflict. Even a rare study examining GRS and romantic relationships measured only intrapersonal expectations (Lopez, Fons-Scheyd, BushKing, \& McDermott, 2011). Without further research, it is impossible to know how similarly these two phenomena operate.

The present study expands upon the GRS literature by examining its relationship with attitudes toward male role norms. It is hypothesized that, like GRC in men, women's GRS negatively predicts progressive other-sex role attitudes. Should the data support this hypothesis, it would suggest that there could be a common factor 
underlying strain from own-gender expectations and role expectations for other-sex individuals. For example, perhaps endorsement of traditional gender roles causes one to hold oneself to similarly traditional ideals and experience strain when those prove unattainable. Or, perhaps a hyperawareness of the strain caused by the expectations for one's own gender provides motivation to enforce the aspects of other-sex expectations with the potential to benefit oneself. As an extreme illustration, consider a woman who devotes herself to being conventionally attractive and feminine. If she supports traditional gender roles, she may expect her husband to provide for her financially in a kind of economic exchange.

\section{Attitudes toward gender roles}

Gender role conflict and stress describe the negative consequences of rigid gender roles for both females and males. However, individuals are not only subject to the role norms of their society; they are also actors who challenge or perpetuate these standards based on their attitudes and associated behavior. Thus, it is important to understand people's attitudes toward the gender roles of the other sex.

Attitudes have often been characterized as evaluations that have both affective and cognitive components (Banaji \& Heiphetz, 2010). For this study, gender role attitudes are defined as an individual's appraisal, positive or negative, of traditional and progressive gender roles. Traditional gender roles dictate appropriate behavior for men and women in aspects of their lives including social situations, romantic relationships, careers, and even grooming habits. The actual content of men's and women's roles varies with time and culture, but their practical effects are primarily the 
restriction of personal freedom and the maintenance of power dynamics (Kilmartin, 2009). Progressive gender role attitudes can be understood as the absence of these restrictions; they acknowledge that traditional gender roles can be harmful to individuals and society as a whole. It is important to note that this perspective is not necessarily opposed to gender normative behavior. Instead, it emphasizes individual choice above societal prescription.

Like racial attitudes, gender role attitudes lie on a continuum from traditional to progressive (Glick et al., 2004). For example, while an individual might believe that men should be allowed to express their emotions, they could simultaneously believe that men are naturally better-suited than women for traditionally masculine jobs. "Egalitarian" is often used interchangeably with "progressive" when describing gender role attitudes, but these terms are not synonymous. Egalitarianism has been defined as including "both beliefs or judgments about the role behaviors of women and beliefs about the role behaviors of men" (King \& King, 1997, p. 72). Thus, it includes comparative attitudes toward men's and women's roles. At its heart, egalitarianism is about gender equality. In contrast, "progressivism” does not necessarily have a comparative component. Rather than balancing the relative roles of men and women, it implies acceptance of a range of genders and questions the validity of prescribed roles for each individual gender. The present research uses the term "progressive" because it focuses on attitudes toward the unique expectations imposed on each gender. 
Previous research has explored the link between masculine ideology—the acceptance of traditional expectations of men - and other-sex gender role attitudes. One early study of male college students found a positive correlation between conservative expectations for women and the masculine norms of status and antifemininity (Thompson \& Pleck, 1986). Opposition to the Equal Rights Amendment was, unsurprisingly, positively related to toughness and antifemininity. Both sets of relationships remained significant after controlling for age, both parents' levels of education, religion, and race, suggesting the validity of these findings across diverse sample characteristics. A more recent study of heterosexual male college students found that endorsement of traditional male role norms, as well as an exclusive masculinity of the ideal self (i.e., the combination of a highly masculine ideal self and highly feminine undesired self) are correlated with traditional views of women's roles (Kilianski, 2003). A related study also found that men's positive attitudes toward traditional male roles negatively correlate with attitudes toward women's equality but positively relate to attitudes conducive of perpetrating sexual harassment toward women (Wade \& Brittan-Powell, 2001). Masculine ideology also predicts sexist beliefs about women (Glick et al., 2004) and negative attitudes toward women's equality (Wade \& Brittan-Powell, 2001).

Women's gender role attitudes are also important to examine. As half the population, women's attitudes toward men's roles undoubtedly influence social expectations and men's experiences. Unfortunately, there are only a few relatively recent studies on this topic, and much of it has been conducted on heterosexual 
romantic couples, limiting the generalizability and theoretical scope. There is a need for research on non-romantic heterosexual relationships. Women and men have many non-romantic interactions in areas of life including work, education, commerce, and recreation. Because people tend to be knowledgeable about and emotionally invested in their romantic partners, romantic relationships represent a unique context. Factors important in that context might behave differently in other kinds of relationships. With the existing knowledge based on few empirical studies and overly distinct participant samples, it is difficult to confidently name the factors influencing women's attitudes toward men's roles.

The literature on the relationship between women's attitudes toward male roles and GRS is even more limited. While there is a large body of research examining how men's GRC relates to their attitudes toward women's roles, there appear to be no published studies examining the equivalent relationship in women: that of GRS and attitudes toward male role norms. As mentioned before, the literature on GRS is largely restricted to symptomology and body image. Even the rare study examining GRS and romantic relationships measures only intrapersonal expectations (Lopez et al., 2011). Assessing the relationship of GRS and attitudes toward male role norms would not only clarify the construct of GRS but could also suggest points of intervention for changing gender related attitudes that are associated with negative health and interpersonal relationship outcomes.

The relationship between GRS and other-sex role attitudes is still unclear. However, neither of these phenomena is necessarily static. Understanding the 
conditions in which they change is a first step toward intentional interventions. Unsurprisingly, the literature on change in GRS is lacking. There is, however, a fair amount of literature on how sex role attitudes change. Several previous studies indicate that traditional gender roles attitudes can change over time and in certain situations. For example, although gender role attitudes have generally become more egalitarian over time (Brooks \& Bolzendahl, 2004; Thornton, Alwin, \& Camburn, 1983) -- even in same-age people from different generations (Fan \& Marini, 2000) -they also change over the course of the lifespan. An eight-year U.S. longitudinal study of youth aged fourteen to 22 showed that women were generally more egalitarian than men, although this gap narrowed as the participants aged (Fan \& Marini, 2000). Participants' education, their mother's employment, and their parents' educational attainment were all positively related to egalitarian attitudes. Within the sample, only women became more egalitarian after entering the labor force and less egalitarian after getting married, although parenthood increased conservatism in both sexes.

Combined, these results suggest that people's attitudes change in accordance with their social environments, although particular life events have differential impacts on women and men.

Situational variables, such as the salience of gender, can also influence attitudes toward male gender roles. One study of dating couples found that both men and women who had a conversation about the intimacy in their relationship (as compared to a discussion of everyday things or no discussion) endorsed more traditional own-gender role attitudes, regardless of participants' own masculinity or 
femininity (Vogel, Tucker, Wester, \& Heesacker, 1999). However, there were no differences in other-sex role attitudes between conditions, and no data were collected on long-term outcomes for participants of either gender. Thus, there is evidence to suggest that priming gender fails to foster short-term change in other-sex role attitudes.

While the causal pathway is unclear, it has also been found that heterosexual women's feminist identity predicts their preferences about the gender role conformity of potential male romantic partners. In contrast to women who identify as feminists, women who reject feminism hold an ideal male partner to the traditional male role norms of emotional control, risk-taking, power over women, dominance, self-reliance, and disdain for homosexuals (Backus \& Mahalik, 2011). This preference could suggest that non-feminist women either seek out men with these traits or encourage them in current romantic partners. If the latter case were true, such women's traditional expectations of men would be fostering in their partners a factor related to such negative outcomes as psychological distress (Mahalik et al., 2003), violence (Courtenay, 2000), and substance abuse (Blazina \& Watkins, 1996). This is not to suggest that women are responsible for the behaviors of their romantic partners; rather, general societal expectations of men often allow negative behaviors such as abuse to continue without serious consequence.

\section{Effects of women's and gender studies coursework on attitudes}

Education is one factor that has been consistently implicated in the increasingly egalitarian gender role attitudes observed during the transition to 
adulthood (Blee \& Tickamyer, 1995; Fan \& Marini, 2000; Tallichet \& Willits, 1986). The present study draws upon previous work in the area of prejudice reduction and attitude change through the completion of undergraduate coursework. Previous research has found that students electing to take women and gender studies (WGS) classes have more egalitarian attitudes (both in general and toward women in particular) and a greater awareness of sexism/discrimination than other students even before completing the course (Stake \& Hoffmann, 2001). One might wonder whether the impact of WGS classes is dependent upon the preexisting attitudes of students choosing to take these classes, since they have been found to be different than those of general student populations. However, the data do not support this hypothesis; WGS course completion predicts a reduction in sexist and gender-stereotyped attitudes even after correcting for initial attitudes (Stake \& Rose, 1994). Additionally, these effects appear to be relatively long-lasting; research has shown that female WGS students' ratings of personal change (including themes such as awareness of discrimination, increased tolerance of others, and adoption of non-traditional behaviors) and feminist activism are sustained at least nine months following course completion (Stake \& Rose, 1994). Thus, past findings on the impact of gender coursework cannot be completely dismissed as the result of situationally specific explicit or subtle demands or expectancies for change placed on the students by course instructors who have power over their grades. In other words, evidence suggests that students' responses are not merely an attempt to please their instructor by answering in alignment with the instructor's perceived desire for them to hold progressive attitudes. Neither does 
change appear to be a result of participating students' fleeting or short-term enthusiasm.

Improved study designs have allowed researchers to show that WGS classes increase egalitarian attitudes and awareness of sexism and other kinds of discrimination relative to non-WGS classes. One study asked university students in WGS and non-WGS classes to describe aspects related to the courses (i.e., perceived pedagogy, relevance to social issues, and student openness to taking WGS classes) as well as their own attitudes (i.e., gender egalitarianism, awareness of sex and general discrimination, current activism, and intentions for activism) and confidence in their performance abilities (Stake \& Hoffmann, 2001). Students also provided qualitative feedback on course effects. Results showed stronger egalitarian attitudes and higher activism scores (but not performance ability) in the WGS classes than the non-WGS classes even after adjusting for initial scores. Taking class composition and relevance of course social issues into account, WGS students still reported stronger course effects than non-WGS students on egalitarian attitudes, awareness of discrimination, and ways of thinking or acting. This study also provided some insight into the impacts of course methods. Validation of personal experience predicted increased general class impact and confidence in abilities. Critical thinking/open-mindedness and political/social understanding and activism related to increases in general class impact, egalitarian attitudes, awareness of discrimination, and confidence in abilities. Participatory learning, however, was negatively related to awareness of discrimination and general class impact (but did not predict subjective measures). Also, the effects of 
class type (WGS or other) remained significant after taking pedagogy into account. Thus, course content might be more important than particular course methods in accounting for possible changes in students' gender role attitudes.

While the aforementioned study found differences in outcomes based on participant variables such as activism and open-mindedness to WGS (Stake \& Hoffmann, 2001), it is likely that other traits also influence the impact of WGS classes on attitudinal change. One participant characteristic that is of particular importance in studies of WGS classes is student gender. Previous studies demonstrating the effects of gender-related courses on attitudes have not found differences in the outcome by sex (Bryant, 2003; Stake et al., 1994; Stake \& Hoffman, 2001; Stake \& Rose, 1994), suggesting that change occurs in both sexes. However, men and women could have qualitatively different responses to WGS classes. Researchers in one study conducted semi-structured and unstructured interviews with eight men in university WGS classes over the course of a semester to determine how they understood feminism (Pleasants, 2011). Early on, men were often sympathetic toward feminism while simultaneously resisting or struggling with the idea. The types of resistance used to preserve male privilege were broadly categorized into "appeals to self," "appeals to progress," and "appeals to authority." Appeals to self included expressions of guilt, taking offense, claiming victimhood, and focusing on intentions rather than actual effects. These reactions were characterized by focusing on oneself to the exclusion of the social context. Guilt in particular became problematic when it failed to pair with perceived opportunities for self-improvement; with no outlet for change, it often turned to 
defensiveness. Appeals to progress involved both over-emphasizing markers of change and believing in the inevitability of inequality. Lastly, appeals to authority included dismissing the validity of women's subjective experiences and leaning on men's supposed objectivity in criticizing feminist strategies (or a lack thereof). These three main patterns of response formed the basis for suggestions to help men understand feminism: bringing the factors that reinforce inequality into the sphere of consciousness, reflecting on one's location within a system of power (including which kinds of discourses are valued or dismissed), and supporting attempts at contributing to change (Pleasants, 2011). Although resistance is frustrating, it is preferable to disengagement.

The methodology used by Pleasants (2011) also offers certain advantages; qualitative data was used to "capture the complexity of participants' experiences and feelings. .." (p. 232). While most studies on the impact of WGS classes use quantitative dependent measures, these measures may not adequately capture the nuances of students' knowledge and beliefs about gender role norms. Mixed-method designs, such as those described by Morgan (2007), can serve as complementary sources of data. Disagreement between the qualitative and quantitative data could indicate that participants were providing disingenuous responses, perhaps to please the professor or to follow the perceived social norms of the situation. Qualitative responses are more complex than most quantitative response options. Not only must they be generated spontaneously, but participants must also understand the perspectives they describe to be able to elaborate upon them successfully. 
Additionally, the answers potentially desired by the researcher or course professor are unobvious. This advantage stands in contrast to the commonly used Likert response scale, on which it is relatively easy for participants to intentionally push answers farther in one direction or the other.

The present study primarily utilizes quantitative data and includes supplementary qualitative data (i.e., narrative responses to the questions "What is a man?" and "What is masculinity?") to better contextualize the quantitative results and provide a more accurate interpretation of the quantitative findings. For example, it is possible that course completion could decrease female students' endorsement of traditional male role norms (which would be evident in the quantitative data) while simultaneously increasing the salience of the different dimensions of traditional masculinity. While the quantitative data is limited to prescriptive ideology, the openended qualitative format used in the present study facilitates an evaluation of the schematicity of traditional male roles. This distinction is important because the undergraduate course being studied could alter or reinforce students' gender schemas through discussions of traditional masculinity's characteristics and negative impacts.

When using education to challenge culturally-ingrained attitudes, it is important to ensure that students' self-reported beliefs are truly their own. Not only do ethical standards oblige professors to create opportunities for students to challenge positions advanced in class, but conducting research in an atmosphere of indoctrination would also invite demand characteristics. Gender studies courses are an easy target for criticism because of the subject's political relevance, and one might 
assume that research in this area is especially prone to validity issues for the same reason. However, a large, geographically diverse study found that both faculty and students perceive women's studies courses as emphasizing critical thinking and openmindedness more than non-women's studies courses (Stake \& Hoffmann, 2000). Women's studies courses are also widely believed to use a participatory learning style (Stake \& Hoffmann, 2000). These characteristics provide some reassurance that WGS classes are not actively encouraging students simply to regurgitate the "right" or socially desirable attitudes on self-report measures.

While WGS classes might emphasize critical thinking and open-mindedness, strong pre-existing attitudes can provide an obstacle to attitude change. For example, non-egalitarian students who rate their WGS class as highly relevant to their own personal issues or to current political issues exhibit less attitude change than nonegalitarian students who find the course less relevant (Sevelius \& Stake, 2003). Interestingly, the same study found that course relevance does not influence attitude change in average- or highly-egalitarian people. Thus, rather than course relevance mediating change, it might instead be moderated by existing attitudes. However, egalitarian attitudes in this study's sample were negatively skewed, creating the possibility that ceiling effects simply made change non-detectable in these students.

Another possible hindrance to the effectiveness of WGS classes is their apparent difficulty attracting men. Among the studies detailed in this section, samples ranged from $88 \%$-91\% female (save Pleasants' (2011) study, which was restricted to male students). Even assuming some volunteer bias, it is clear that there is a gender 
imbalance in WGS classes. Whether men are resistant to the perspectives advanced in these classes, as suggested by Pleasants (2011), or decline to enroll in them for some other reason is unclear. Instructors who teach gender-related courses and who seek to attract more male students should be particularly thoughtful in their presentation of material that is directly threatening to men, such as the topics of male privilege and gendered violence. This strategy could involve a related increase in content that addresses the impact of gender role norms on men (such as GRC) and on the development of healthy or positive masculinities. Classes specifically on the psychology of men and/or masculinity, which fall under the WGS umbrella, would be an excellent place to do this work. However, it remains to be seen whether these courses are effective in changing students' gender role attitudes.

\section{University courses on the psychology of men}

While less studied than WGS classes focused on women, classes on men and masculinity have received some attention in the psychological literature. Much of the work has been descriptive, which in future research will be useful for identifying differences and similarities between women's and men's studies courses. Readers unfamiliar with men's studies courses may be surprised at the ideological perspectives of many instructors. Specifically, deconstructing masculinity has been described as a feminist endeavor (O’Neil \& Renzulli, 2013a); rather than the wearisome patriarchal pedagogy one might expect from a class focused explicitly on men, instructors of the psychology of men are using the opportunity to explain sexism and the cost of restrictive gender roles. A complex interplay of factors has limited the prevalence of 
psychology of men classes and their popularity relative to psychology of women courses (O’Neil \& Renzulli, 2013a). However, these courses offer a unique perspective from which to disrupt the status quo. One study (which included the professor of the course examined in this paper in its sample of 44 professors) has documented that the vast majority of courses on the psychology of men include discussions of multiculturalism and diversity, inclusion of sexual minorities, oppression in men's lives, positive aspects of masculinity, and negative aspects of masculinity (O’Neil \& Renzulli, 2013b). These are challenging topics, and it is unsurprising that the professors of these courses commonly reported difficult classroom dynamics and defensiveness in some of their students.

At the same time, professors of these courses often witness students' excitement and personal development (Mahalik, Addik, Kilmartin, \& O’Neil, 2013). Women in psychology of men courses have been described as learning to empathize "...with the men in their lives as they come to see both men and women as enduring similar experiences that shape them and often silence them," and male students connect with the material based on their personal experiences (Mahalik et al., 2013, p. 248). However, it is difficult to make claims about the impact of these courses without empirical research. One of the main purposes of the present study is to determine whether female students in a psychology of men and masculinities course experience changes in their attitudes toward male role norms.

\section{Anticipated change in students' gender role attitudes}


The Psychology of Men and Masculinities course being studied had been taught in a manner close to its current format by the same male professor for over a decade, and the syllabus stayed the same across both samples examined in this study. Students' gender role attitudes and definitions of men and masculinity are expected to change from the beginning to the end of the class for several reasons. These reasons include the course content, the social atmosphere of the class, and certain elements of the course process. One excellent review of the literature on attitude change and resistance posited that these are driven by three primary motivations: a desire to validly understand reality, concerns with the positivity and consistency of the self, and concerns with others and their reactions to oneself (Wood, 2000). The concept of backlash effect (Rudman, 1998), which has been previously discussed, exemplifies the second of these motivations; people may adjust their gendered behaviors in order to avoid negative repercussions from others.

The first possible cause of change in students' male role attitudes is the course content. This factor is related to the motivation to hold a valid understanding of reality. In other words, if the perspectives advanced in the course are persuasive, a student is likely to change their attitudes to align with their new understanding of reality. Course content involved a variety of sources, regarding both authorship and presentation, and it covered a range of topics relevant to men's daily lives. Students primarily read The Masculine Self(Kilmartin, 2009) and selected articles from the Men's Lives reader (Kimmel \& Messner, 2012), although supplemental materials were also presented. The course material was divided into three main units. The first was 
psychological and sociobiological theories of masculinity. Topics included various lenses of masculinity (e.g., biological, social, psychoanalytic), gender role conflict, theories of masculine development, and diversities of masculinity (i.e., race, class, and sexual orientation). The second unit focused on masculinity and relationships.

Material focused on men's sexuality and pornography, including the expectations that men are heterosexual and innately hyper-sexual; friendships between men and homophobia; parenting and partnering; and violence and emotions. The last unit was on men and society, with material on work (e.g., dangerous male-dominated careers, pressure to fulfill the role of breadwinner), sports and competition (with particular emphasis on aggression), physical and mental health, and men's movements and politics. Restrictive emotionality was discussed in regards to its negative impact on relationships and health behavior. Throughout the course, students were encouraged to engage with the material critically and apply their scientific knowledge to consider how they might test certain ideas being presented. Not only were students exposed to a variety of concepts, but they also practiced applying these concepts to their own experiences (making the material more personally relevant).

One point that was revisited throughout the course was the negative impact of restrictive conceptualizations of masculinity. In every unit, students explored the negative outcomes associated with behaviors in a particular domain. For example, students learned how the masculine role norms of aggression and dominance facilitate risky behavior and exposure to, as well as perpetration of, violence. Similarly, the link between restrictive emotionality and negative psychological outcomes was illustrated. 
This focus on harmful consequences is one major facet of the course that could decrease students' endorsement of traditional male norms. Related research has shown that providing men and women with information on the harmful consequences of benevolent sexism, an ideology that patronizingly advocates women's inherent goodness but lack of agency (see Glick and Fiske, 1996 for a full definition), successfully reduces their endorsement of such attitudes (Becker \& Swim, 2012). This effect remained significant even after controlling for measures of social desirability. While long-term impacts on attitudes were not assessed in the aforementioned study, it is also important to note that exposure to the experimental manipulation was brief. This stands in contrast to an undergraduate class, where information on the harmful effects of particular gender attitudes is both in-depth and regularly reinforced through reflection and examples in many different domains.

The structure of the course being studied, which encourages deep intellectual involvement with the material, is especially conducive to attitude change. In both samples examined in this paper, the course lasted ten weeks with two 110 minute classes per week. While attendance was not mandatory, students were required to attend the first class meeting of the week to receive credit for their weekly reaction papers based on the readings. These papers were discussed in small groups of three to five peers for about half an hour weekly. The rest of the course time was divided between lectures, discussions involving the entire class, and presentation of relevant outside media. In addition to weekly papers, students were responsible for completing a midterm exam, a final project (interview, observation, or literature review), and a 
final exam. Thus, engagement with the material was intense and involved multiple modes. In addition to absorbing the material through lecture and independent reading, students had opportunity to reflect individually on the material through the writing assignments and in conversation with their peers. While students were encouraged to examine the material with appropriate scientific skepticism, it seems plausible that by participating in the course, students develop a deeper understanding of masculinity and the social normative pressures underlying its socialization, and that this knowledge influences them to adopt more progressive gender role attitudes.

Social processes are the third main factor expected to encourage students' attitude change. Many of these relate to the desire that others hold a favorable impression of the self(Wood, 2000). As students are regularly asked to discuss and write about their opinions and experiences relating to gender, they gain a great deal of exposure to the ideals of their peers. Past research has found that group discussions tend to increase group consensus on both discussed topics and topics related to those discussed (Binder \& Bourgeois, 2006). And, it has been found that prototypic group attitudes are particularly influential because they support the image of expertise and validate the views of other group members (Wood, 2000). Of course, such social normative processes could actual increase students' traditional male role attitudes if most students tended to agree with them at the beginning of the class. Whether average gender role attitudes are more or less progressive than those found in other studies remains to be seen. However, several factors make it likely that opinions expressed in these group discussions are generally in line with the progressive 
perspective presented. Considering that the psychology of men and masculinities class is an elective, students are presumably interested in the topic and could already hold an unusually nuanced understanding of masculinity. Additionally, it seems reasonable to expect that the professor's progressive beliefs about gender create an environment conducive to the expression of similar beliefs among students. Students who agree with the views presented in class are probably more comfortable sharing their views publicly. Then, normative social influence or a desire to please the professor could drive students who hold traditional male role attitudes to express different attitudes than those they actually possess.

One study on the influence of WGS classes examined the impact of both course expectations and interpersonal factors on attitude change. It was found that students' positive expectations about the class and capacity for forming relationships predicted change in egalitarian gender role attitudes, among related measures (Malkin \& Stake, 2004). Additionally, this relationship was mediated by perceived alliance with the professor and cohesion with classmates. In other words, both pre-class expectations and social interactions engaged in during the course have important roles in changing students' gender-related attitudes.

Returning to the issue of social desirability, one might argue that social influence in the classroom would fail to impact individuals' enduring attitudes or even cause reactance. However, research has provided evidence that social motives for agreement can extend into the private realm in a number of different ways. Motives from prior settings that have ceased to be salient can influence the judgments or 
information an individual retrieves in a new setting (Wood, 2000). Thus, a class setting, in which students consider particular perspectives both publicly and privately (as during the completion of homework) for an extended period of time, could influence attitudes both through the creation of social norms and the strengthening of cognitive associations in other settings.

Cognitive associations are especially important for the qualitative component of the present study. As previously discussed, responses to the open-ended questions "What is a man?" and "What is masculinity?" are used to bolster the quantitative measure of students' endorsement of different male role norms. Thus, coding themes were determined inductively to correspond to the dimensions of the MRNI. However, the interpretation of these data is complex. Students who decrease their endorsement of masculine role norms could mention fewer such norms, opting instead to focus on different dimensions. Alternatively, the class could have created or enhanced students' schema of traditional masculinity. A student leaving the class with a clearer schema of traditional masculinity might describe the role norms while simultaneously drawing attention to their harmful effects or stating that while these role norms exist broadly in society, the individual students disagrees with them. In this instance, it might be desirable to code responses based on a ratio of traditional or progressive ideas to the total number of ideas presented in order to correct for an increase in the occurrence of traditional dimensions of masculinity simply from their increased salience. As discussed below, the nature of the data prohibits a coding system that differentiates between positive and negative endorsement of any dimension named by 
participants. Despite these challenges, the qualitative data offers a unique opportunity to understand how students are naturalistically thinking of men and masculinity.

\section{Present study}

While courses on the psychology of men have been suggested as a way to empower men, promote healthy masculinity, and educate people about the challenges faced by men (O’Neil \& Renzulli, 2013), research on the impact of participating in a course on the psychology of masculinity is lacking. Consequently, this research project has two main purposes. The first purpose is to evaluate female students' attitudes toward male role norms in a course on the psychology of men and masculinities. To address this purpose, data were collected bearing on two specific research questions: 1 . Do female students' attitudes change from the beginning to the end of the course? and, 2. Do students' attitudes at the beginning of the course differ from those enrolled in required psychology course that does not address gender? The second purpose of this research project was to determine 3. How do female students' attitudes toward male role norms relate to their feminine gender role stress?

The present research addresses these research questions in three separate studies using samples of students in a psychology of men and masculinities course and, as a control group, a sample of students in a research methods psychology course that does not address gender. Data in all three studies were collected from female undergraduate students at the same large, urban university in the Pacific Northwest. Table 1 shows the samples used to test each hypothesis as well as the effect sizes required to find significance (at power $=.80$ ). These statistics were calculated based 
on sample size and criterion alphas for significance, applying the Bonferroni method to adjust for multiple tests where applicable, using $\mathrm{G}^{*}$ power software (Faul, Erdfelder, Lang, \& Buchner, 2007). 


\section{Study 1}

The first part of Study 1 assesses change in female students' attitudes toward male roles by comparing pre-class and post-class scores in the 2011 Psychology of Men and Masculinities course. The second part uses an open-ended questionnaire format to assess changes in female students" narrative definitions of "man" and "masculinity" from the beginning to the end of the class. Responses are coded for the seven theorized components of male gender role expectations comprising the MRNI (Levant et al., 1992), which is described in greater detail below.

Research Question 1. Do women's attitudes toward male role norms change from the beginning to the end of a class on the psychology of men and masculinities?

Hypothesis 1a. As one of the implicit goals of the course is to expose students to broader perspectives of gender, I hypothesize that attitudes about male gender role norms are more progressive at the end of the course than at the beginning. In other words, it is expected that average scores decreased on each of the three factors of the MRNI as well as on the total score.

Hypothesis 1b. Students' definitions of the terms "man" and "masculinity" are coded for the presence or absence of the seven theorized dimensions of male role norms used in the MRNI (Levant et al., 1992). These dimensions are: avoidance of femininity, fear and hatred of homosexuals, self-reliance, aggression, achievement/status, non-relational attitudes toward sexuality, and restrictive emotionality. Each subscale is described in greater depth in the Measures section. I hypothesize that these codes have fewer occurrences at the end of the course than at 
the beginning. However, as previously discussed, it is also not unlikely that occurrences increase as their schematicity increases.

\section{Method}

\section{Participants}

Participants in Study 1 were students enrolled in the 2011 Psychology of Men and Masculinities course, an upper-level elective psychology course. Several students added or dropped the class after the beginning of the academic quarter, but response rates are calculated based on the total number of students who were registered for the course at any time (the only official enrollment information available). Response rates could be impacted by several factors. Data at the first time point are missing from students who declined to participate or who were not yet enrolled in the course. Data at the second time point are missing from students who declined to participate, dropped the course earlier in the term, or chose not to attend the final exam session in which the questionnaire was administered. Of the 41 students in the course who identified as women, $24(58.5 \%)$ responded to the quantitative questionnaire at the beginning and $33(80.5 \%)$ at the end of the course. The final sample consisted of the $19(46.3 \%)$ women who completed the quantitative measure of attitudes toward male roles (MRNI) at both the beginning and the end of course.

The sample of women providing qualitative data was somewhat different. Forty women, or $97.6 \%$ of all female students enrolled in the course at any point in the quarter $(N=41)$ provided qualitative data at the beginning of the course, and 34 
$(82.9 \%)$ provided data only at the end. Thirty-two (78\%) provided both pre and post course data, and analysis was restricted to this sample.

\section{Measures}

Women's attitudes toward men's roles. Students who identified as women were asked to complete the Male Role Norms Inventory (MRNI; Levant et al., 1992), which evaluates attitudes toward male roles. This 58-item scale asks respondents to rate their agreement with items on a scale from $1=$ strongly disagree to $7=$ strongly agree. However, the instructor of the Psychology of Men and Masculinities class modified the scale to range from $1=$ strongly disagree to $6=$ strongly agree in order to avoid providing a neutral choice. There are seven subscales describing prescriptive characteristics for males: avoidance of femininity (e.g., "A man should prefer football to needlecraft"), homophobia (e.g., "It is disappointing to learn that a famous athlete is gay"), self-reliance (e.g., A man should never count on someone else to get the job done"), aggression (e.g., "When the going gets tough, men should get tough"), achievement/status (e.g., "A man should always be the major provider in his family"), non-relational attitudes toward sexuality (e.g., "A man shouldn't bother with sex unless he can achieve an orgasm"), and restrictive emotionality (e.g., "Nobody likes a man who cries in public"). Due to an error in data collection, one item from the achievement and status scale (i.e., "Men should have goals and be determined to achieve them") was excluded. The original validation sample was similar to the one examined here, consisting of primarily undergraduate women and men. While the MRNI has been revised several times in recent years (e.g., Levant et al., 2007b), the 
professor of the masculinities course had selected the original version more than a decade prior to the present study because it mapped well onto the content of the course. For consistency, the same version has been used in data collection over the years. Changes in later versions of the scale and corresponding improvements in reliability are considered in the discussion.

While the seven subscales were derived from theory, factor analysis in the original scale validation only supported a three-factor model (Levant et al., 1992). Two of the factors are the self-reliance and aggression subscales, respectively, and the third is a combination of the remaining five theorized sub-dimensions (i.e., avoidance of femininity, homophobia, achievement/status, non-relational attitudes toward sexuality, and restrictive emotionality). Some of the subscales have had poor to moderate internal reliabilities in previous research (Levant et al., 2007b), but a study similar to the present one — with female and male university students — had high reliability ( $\alpha=.93$; Levant et al., 1992). In Study 1, Cronbach's alpha for the total scale was .88 at both pre- and post-class.

The MRNI has shown good discriminant and convergent validity. While it is not related to the Personal Attributes Scale (a measure of gendered personality traits) in either men or women, it is moderately correlated with men's gender role conflict (Levant et al., 2007b). The majority of studies using the MRNI have administered the measure to male populations, in which it has been shown to relate to negative attitudes about women's equality (Wade \& Brittan-Powell, 2001), attitudes about sexual 
harassment toward women (Wade \& Brittan-Powell, 2001), and relationship violence (Levant et al., 2007b), among others.

Qualitative definitions of men and masculinity. Students' definitions of men and masculinity were collected through open-ended, written responses to two questions: "What is a man?" and "What is masculinity?" The questions were not elaborated upon, and students answered them individually. Gender of students was determined by linking the name written on the questionnaires to the students' selfpresentation in class and by verifying this subjective judgment against the quantitative questionnaire they chose to complete (female-identified students were asked to complete the Male Role Norms Inventory, and male-identified students were requested to complete the Gender Role Conflict Scale during in-class assessments).

Definitions and examples of each coding theme are given in Table 2. Responses were coded for the dimensions of male role norms described in the MRNI: avoidance of femininity, restrictive emotionality, aggression, achievement/status, selfreliance, fear and hatred of homosexuals (homophobia), and non-relational attitudes toward sex. The masculinities course referenced these themes explicitly in lecture and in the readings. Students were encouraged to interpret various aspects of male behavior by mapping them onto these norms; for example, men's sexual scripts could be related to aggression and achievement/status in addition to the more obvious nonrelational attitudes toward sex.

\section{Procedure}


On the first day of class, the professor of the psychology of men and masculinities class introduced the questionnaires as an educational experience relating to students' gender role attitudes. To avoid priming the particular subscales of the MRNI, qualitative data were collected first. Students were handed a sheet with the questions "What is a man?" and "What is masculinity?" and asked to write a response in class. Students also wrote their first and last names on these papers and returned them to the instructor when they were finished. Next, the quantitative questionnaires were distributed. Female-identified students were instructed to complete the paper questionnaires containing the MRNI, and male-identified students completed a paper questionnaire with a measure of male gender role conflict. Students were asked to write the last four digits of their student ID numbers on the top of the questionnaires, but not their names, before handing them in to the instructor.

Post-class data were collected directly prior to the final exam session. First, students were given fresh papers with the questions "What is a man?" and "What is masculinity?" and asked to write their name at the top and provide their definitions. After students were finished writing, the instructor passed back each students' preclass responses for them to compare their answer at each time point. Quantitative questionnaires were then distributed, with female-identified students again completing the MRNI and male-identified students completing a measure of male gender role conflict. Students were asked to write the last four numbers of their student ID at the top, and this information was used to match pre- and post-class responses. Responses 
to the qualitative data were matched using students' first names, which were subsequently removed from the data.

\section{Analysis}

Hypothesis 1a. After reverse-scoring the appropriate items as described by Levant et al. (1992), total and subscale means on the MRNI were calculated for each participant who provided data on at least $80 \%$ of the items comprising each subscale.

Next, the internal consistency of each subscale of the MRNI was examined by calculating Cronbach's alpha (see Table 3), and some were found to be concerning. In the social sciences, Cronbach's alphas above .70 are generally considered acceptable, although problems with this convention have been noted (e.g., Cortina, 1993). Factor 1 had generally high alphas across all samples examined in this study, with the lowest at .77. However, the internal reliabilities of the aggression subscale ranged from .65 and .69 , and the self-reliance subscale had reliabilities from .07 to .68 . Inspection of the inter-item correlation matrices and item-total statistics revealed that reliability of the self-reliance subscale would be moderately improved in three samples by deleting MRNI item 21 ("A man who takes a long time and has difficulty making decisions will usually not be respected"). To maintain consistency across samples and studies, this item was deleted from all the samples examined in this paper.

It is important to note that while deletion of item 21 improved reliability in most samples, it reduced Cronbach's alpha in the Research Methods sample (examined in Study 2) to -.10. A negative Cronbach's alpha means that the average inter-item covariances are negative (Nichols, 1999), demonstrating that these items 
likely do not represent a single construct in this population. While removal of MRNI item 10 ("A man must be able to make his own way in the world") would increase this reliability to .40 (the maximum possible with removal of only one item), this action would also severely decrease the reliabilities of this subscale in the other samples. Examination of the data showed no extreme outliers, defined as three standard deviations or more from the mean, in this sample. Having ruled out unusual data or poorly-fitting items as the cause of this reliability issue, further improvement in this sample was not attempted. Results utilizing this subscale in the Research Methods sample must be interpreted with extreme caution. In all other cases, adjusted selfreliance alphas ranged from .52 to .74 across samples and time points.

Hypothesis 1b. It is hypothesized that female students' narrative definitions of "man" and "masculinity" change from the beginning to the end of the Psychology of Men and Masculinities course such that they include fewer mentions of the traditional male gender role norm components described in the MRNI. Levant et al. (1992) does not explicitly define each dimension, so brief definitions were devised by summarizing the prescriptive ideals behind the items in each theorized dimension. Examples illustrating each concept were pulled from the data. This initial coding scheme and a copy of the original MRNI were provided to an undergraduate research assistant (RA1) who had previously completed the Psychology of Men and Masculinities class. The primary researcher reviewed the coding scheme with RA1 and trained her in the qualitative data analysis software NVivo Version 8 (QSR International), which was used for the coding and analysis. Next, the coding scheme 
was piloted in equivalent data from a different class year. The scope of each code was refined through discussion between the primary researcher and RA1 as they independently coded the data. The items of the original MRNI subscale were consulted in determining the scope of each code to attempt to maintain consistency in interpretation. After this process, the coding scheme was finalized (see Table 2).

Because most responses were short, usually a phrase to a few sentences, it was decided that cases (combining responses to both questions) would be the unit of analysis. Combining responses to the two questions answered by each participant, pre-class responses ranged from 21 to 134 words $(M=63.0, S D=28.9)$, and postclass responses ranged from six to 154 words and were only very slightly longer and somewhat more variable in length $(M=70.1, S D=35.2)$.

Coding of these themes was completed in three stages: data blinding, coder training, and coding. Firstly, the primary investigator assigned a random, unique identification number to each response, defined as a participant's combined answers to both questions (i.e., "What is a man/masculinity?") at either the beginning or end of the class, so that an individual participant's pre-class and post-class responses could be matched. Thus, coders were blind to the time point at which a response was given.

Next, the primary investigator trained a second undergraduate research assistant (RA2), who had also completed the Psychology of Men and Masculinities class, to understand the finalized coding scheme and to code responses using the NVivo software. Both coders, RA1 and RA2, were instructed to code for the mere presence of a theme in a response regardless of explicit or implicit participant 
endorsement. In other words, a code was applied each time any of the seven male role norms was referenced regardless of the context. Because of the variety in responses, which is discussed later, it was not feasible to code for participant agreement or disagreement with each norm referenced. Implications of this decision are considered in the discussion.

After being familiarized with the coding scheme, RA1 and RA2 independently coded the pre- and post-class responses from a different year of the class than the one being examined in the present study, a total of 76 responses. An interrater reliability analysis using the kappa statistic was performed to determine rater consistency. According to the commonly accepted guidelines in psychology, values of Cohen's kappa ranging from .41-.60 are considered moderate, .61-.80 substantial, and .81-1.00 almost perfect (Landis \& Koch, 1977). Because researchers often use .60 or .70 as cutoffs of acceptability, the present study conservatively deemed $\kappa \geq .70$ acceptable. High interrater reliability was achieved in the pilot sample. The average kappa across codes was .86. Also high in interrater reliability were the individual codes of achievement/status $(\kappa=.86)$, aggression $(\kappa=.79)$, antifemininity $(\kappa=.82)$, homophobia $(\kappa=1)$, self-reliance $(\kappa=.78)$, restrictive emotionality $(\kappa=.94)$, and attitudes toward sex $(\kappa=1)$. It is important to note that the perfect interrater agreement on the codes for homophobia and attitudes toward sex was due to a complete absence of these themes in the pilot sample. There was no reason to expect that they would be more common in the study sample, so rather than code responses from another class unrelated to the present study in the hopes of capturing the 
presence of these two themes, the researcher decided to proceed to coding the study sample.

After it was determined that kappas in the pilot sample were acceptable, RA1 and RA2 then independently coded the study data itself. The coding scheme and kappas for each code are shown in Table 2. The overall coding scheme had a kappa of .89 , which is considered excellent. Interrater reliabilities were also high for achievement/status $(\kappa=.86)$, sex attitudes $(\kappa=1)$, restrictive emotionality $(\kappa=.84)$, aggression $(\kappa=.97)$, and homophobia $(\kappa=1)$. As in the pilot coding, the perfect agreement for the homophobia code $(\kappa=1)$ was due to a total absence of the theme in the data. However, the theme of nonrelational sex attitudes, which also had perfect agreement $(\kappa=1)$, was present in this data set. The interrater reliabilities for antifemininity $(\kappa=.65)$ and self-reliance $(\kappa=.68)$ were just below the predetermined cutoff. As it was decided before any coding was begun, the remaining coding discrepancies were resolved by a new independent coder, the professor who taught the Psychology of Men and Masculinities course. Lastly, responses were sorted back into pre- and post-class data based on their identification numbers.

\section{Results}

Hypothesis 1a. The data consisted of total and MRNI subscale scores for female students in the Psychology of Men and Masculinities class who provided data at both the beginning and the end of the course. The total MRNI mean was higher pre-class $\left(M_{1}=2.39, S D_{1}=.35\right)$ than post-class $\left(M_{2}=2.11, S D_{2}=.36\right)$. This decrease from pre- to post-class was also exhibited by the means for Self-reliance $\left(M_{l}=3.57\right.$, 
$\left.S D_{1}=.61 ; M_{2}=3.14, S D_{2}=.76\right)$, Aggression $\left(M_{1}=3.15, S D_{1}=.61 ; M_{2}=2.72, S D_{2}=\right.$ $.72)$, and Factor $1\left(M_{l}=2.07, S D_{l}=.34 ; M_{2}=1.85, S D_{2}=.31\right)$. See Figure 1 for a visual representation of this change.

To determine whether women's attitudes toward male role norms changed from the beginning to the end of the Psychology of Men and Masculinities class, paired-samples $t$-tests were conducted for total MRNI scores as well as for the three subscales (see Table 4). Adjusting for the number of tests using the Bonferroni method, the critical $p$ value was 0.0125 . Total MRNI scores significantly decreased from the beginning to the end of the class, $t(18)=4.31, p<.000, d=.79$. Scores on Factor 1 also significantly dropped, $t(18)=3.50, p=.003, d=.68$, as did Aggression scores, $t(17)=3.24, p=.005, d=.645$. Lastly, scores in the self-reliance subscale decreased, $t(18)=2.79, p=.012, d=.62$. Achieved power, assuming equivalence between sample and population values, ranged from .72 to .90 (see Table 4). All of these tests were significant regardless of whether or not item 21 was deleted from the measure.

Post-hoc analyses were conducted to improve the interpretability of the change in Factor 1 scores. The factor structure of the original MRNI does not support the interpretation of the individual dimensions of achievement/status, antifemininity, homophobia, restrictive emotionality, or nonrelational sex attitudes (Levant et al., 1992). However, the combination of these different norms into one factor obscures its meaning. Testing pre- to post-class change in these dimensions individually, it was discovered that they did not all display the same pattern of change. The largest 
decreases in endorsement were shown for the norms of achievement/status $\left(M_{l}=2.26\right.$, $\left.S D_{1}=.46 ; M_{2}=1.95, S D_{2}=.42\right), t(18)=4.60, p<.000, d=.70$, and antifemininity $\left(M_{1}=1.92, S D_{1}=.67 ; M_{2}=1.57, S D_{2}=.52\right), t(18)=4.69, p<.000, d=.58$.

Nonrelational sex attitudes also decreased $\left(M_{1}=2.22, S D_{1}=.41 ; M_{2}=1.99, S D_{2}=\right.$ $.42), t(18)=2.85, p=.01, d=.55$. However, both restrictive emotionality $\left(M_{1}=1.98\right.$, $\left.S D_{1}=.34 ; M_{2}=1.85, S D_{2}=.45\right)$ and homophobia $\left(M_{1}=1.85, S D_{1}=.39 ; M_{2}=1.82\right.$, $S D_{2}=.56$ ), which had the lowest endorsements at the beginning of the class out of all the components of Factor 1, barely and nonsignificantly decreased, $t(18)=1.11, p=$ $.28, d=.33 ; t(18)=.20, p=.84, d=.06$.

Hypothesis 1b. Thirty-two female students in the Psychology of Men and Masculinities class provided responses to the questions "What is a man?" and "What is masculinity?" at both the beginning and the end of the class. Descriptive statistics for each code at both time points are reported in Table 5. A graphic display of the relative presence of each theme, reported as a number of respondents mentioning the theme in response to either question at the beginning and at the end of the class, is provided in Figure 3. The theme of aggression was the most commonly referenced male role norm both at the beginning $\left(\mathrm{n}_{1}=18,56.3 \%\right)$ and the end of the class $\left(\mathrm{n}_{2}=8\right.$, $25.0 \%)$, as well as across both time points $\left(\mathrm{n}_{\text {total }}=26,40.6 \%\right)$. Achievement $/$ status was the next most commonly discussed theme at the beginning of the class $\left(\mathrm{n}_{1}=15\right.$, $46.9 \% ; \mathrm{n}_{2}=7,21.9 \% ; \mathrm{n}_{\text {total }}=22,34.4 \%$ ). Following in prevalence were restrictive emotionality $\left(n_{1}=8,25.0 \% ; n_{2}=4,12.5 \%\right)$, self-reliance $\left(n_{1}=4,12.5 \% ; n_{2}=3\right.$, 9.4\%), and non-relational attitudes toward $\operatorname{sex}\left(\mathrm{n}_{1}=2,6.3 \% ; \mathrm{n}_{2}=2,6.3 \%\right)$. The 
theme of avoidance of femininity $\left(\mathrm{n}_{1}=0 ; \mathrm{n}_{2}=4,12.5 \%\right)$, while completely absent in the pre-class responses, was the fourth most common theme at the post-class. As mentioned earlier, fear and hatred of homosexuals/homophobia was entirely absent at both time points.

To determine whether the prevalence of male role norms in these responses was different at the end of the class than it was at the beginning, a series of exact McNemar's tests were conducted (see Table 5). There were significantly fewer mentions of the norms of achievement/status, $p=.02$, and aggression, $p=.01$, at the end of the class than at the beginning. The presence of avoidance of femininity, $p=$ .13 , non-relational attitudes toward sex, $p=1$, restrictive emotionality, $p=.34$, and self-reliance, $p=1$, did not differ between the time points. However, an analysis of achieved power indicated that only the first two tests had sufficient power (generally defined as $>.80$ ) to detect true differences. Thus, while the prevalence of homophobia and non-relational sex attitudes did not change over time, it is possible that this study was underpowered to detect true decreases in the prevalence of avoidance of femininity, restrictive emotionality, and self-reliance.

It is also important to note that many responses did not mention any of the male role norms included of the MRNI (see Figure 4). At the beginning of the class, $13(41 \%)$ of responses did not mention a single male role norm, a number that rose to $21(66 \%)$ at the end of the class. Seventeen (53\%) referenced between one and three role norms at pre-class, and eight $(25 \%)$ did at post-class. Two people $(6 \%)$ at pre- 
class and three people ( $9 \%$ ) at post-class referenced four role norms, the most observed.

\section{Discussion}

Hypothesis 1a. Generally, women in the Psychology of Men and Masculinities class disagreed or slightly disagreed with the male role norms assessed by the MRNI. Subscale means and standard deviations across all samples included in this study were slightly lower than those reported for females in Levant et al. (1992) and Levant, Majors, and Kelley (1998), two of a handful of published articles that administered the original MRNI to women in the United States, even after adjusting for the decision to use a 6-point rather than a 7-point scale in the present study. In the two studies mentioned above, women's scores for the total scale and Factor 1 leaned toward "slightly disagree," while they were closer to "disagree" in the present sample. Similarly, the previous research found women to generally respond between "neutral" and "slightly agree" to the aggression items, whereas the women in this sample ranged between "slightly disagree" and "slightly agree," which could be interpreted as neutral endorsement. Self-reliance scores in this study were comparable to those in previous studies, ranging between "neutral" and "slightly agree." Some of the minor differences could be a result of the discrepancy in the range of the Likert scales, namely that participants in this study were not afforded an explicitly "neutral" response option. However, it could also be a result of increasingly progressive attitudes over time or the fact that the university is located in a mostly White and politically liberal city, as past research has found that MRNI endorsement tends to be 
lower in European American and Northern populations in the U.S. (Levant \& Richmond, 2007).

The hypothesis that the total and subscale means of the MRNI would be lower at the end of the class than at the beginning was supported. Female students' endorsement of the total set of male norms, the norms of aggression and self-reliance, and Factor 1 all significantly decreased with medium effect sizes (all scores were between $65 \%$ and $79 \%$ of a standard deviation lower post-class). These data are consistent with an interpretation that these female students' involvement in the Psychology of Men and Masculinities course reduced their endorsement of male role norms in general as well as the specific norms of aggression, self-reliance, and the components of the MRNIs Factor 1. However, unfortunately, given the quasiexperimental design of the study, it is not possible to rule out other possible interpretations. The changes may have resulted from demand characteristics placed on the students by the instructor or other peers in the course, or by external sociohistorical factors. In regard to demand characteristics, students could have been motivated to respond in accordance with the perceived social norms of the class, or they could have felt pressure to be a "good participant" after inferring, based on the course material, that the professor held progressive gender ideals. This second possibility is particularly concerning given that the professor who taught the course also administered the measures. In regard to sociohistorical factors, to the author's knowledge, there were no major historical events during the duration of the class that would have been likely to influence these attitudes. A search of the university 
newspaper archives for the relevant time period returned no results for "masculinity," "masculine," or "gender." Additionally, of four results for the search term "man" in the online university newspaper archives, none were focused on gender. Were there major events of relevance to all of the students at the university, is it likely that they would have been mentioned in this paper.

Given the possibility of reactance to gender-focused education, it is also interesting to consider possible alternative response patterns within the larger dataset. Specifically, the significant decreases in the MRNI total, aggression, and Factor 1 scores were not uniformly present in every individual participant's response. Of the 19 women in this sample, all but three $(15.8 \%)$ had lower MRNI scores at the end of the class than at the beginning. Closer examination was given to the scores of these three participants for exploratory purposes. Specifically, I was interested to see whether evidence of reactance to the progressive course material would emerge. The participants who did not display decreased endorsement of male role norms over time had total scores that were an average of .15 points higher at the end of the class. On the MRNI's Likert scale of one to six, this mean score increase is essentially negligible. Within these participants, there was no clear pattern of change across the three subscales of the MRNI. Neither did they have particularly high scores at the beginning of the class $(M=2.17)$, which could have suggested reactance to the progressive course material; if they had held strongly traditional attitudes, perceived pressure from the course to adopt more progressive attitudes could have further strengthened their existing beliefs. Thus, it is unclear whether these participants were 
meaningfully different than the others in the sample. Future research could examine different response patterns in students taking WGS courses to determine whether students with certain characteristics respond particularly well or poorly to the experience. In addition to reactance, there is also the possibility of students with extreme change toward more progressive attitudes. In other words, perhaps some students entering the class with highly traditional gender role attitudes are deeply impacted by the course and display a greater shift toward progressive attitudes than other students.

Hypothesis 1b. Analysis of the open-ended responses to "What is a man/masculinity?" revealed that there were significantly fewer references to the male role norms of aggression and achievement/status at the end of the class than at the beginning. The norms of avoidance of femininity, non-relational attitudes toward sex, restrictive emotionality, and self-reliance did not significantly differ across time. Additionally, the norm of homophobia was not referenced by participants at either time point. This absence of homophobic norms could result from the socially liberal culture of the university, or it could simply indicate that sexuality is less salient than the other norms. Supporting this interpretation is the corresponding lack of attention to heterosex in the dataset (which would correspond to the norm of non-relational sex attitudes).

The decreased prevalence over time of the norm of aggression is more complicated than it might sound. At the beginning of the class, the majority of the students referenced this norm casually by defining men/masculinity as "strong" or 
“tough.” For example, "I believe masculinity to be Personality traits; tough, testosterone, confidence in ability, etc. ..." (Effort was made to differentiate between the uses of "strong" as athletic versus resilient, but this was occasionally difficult to determine.) There was somewhat more diversity in how this norm was described postclass. It was rarely presented as being wholeheartedly endorsed at either time point; it was normally framed in terms of societal expectations. Interestingly, six people referenced this norm at both the beginning and the end of class. These respondents seemed aware of the constructed nature of this norm, referencing stereotypes and social scripts. At the beginning of the class, one participant wrote, "Masculinity, to me, is a real but socially constructed performance given by humans who want to express themselves like as $[$ sic $]$ a "man." [S]ome examples for me are: strong ...." This example shows that a simple decrease in the presence of this theme does not necessarily equate to a decrease in endorsement, since many participants qualified their views on the norm at both time points. It appears that at least some students are referencing these commonly-held norms specifically to explain that they disagree with them. In line with this hypothesis, the two explicitly negative mentions of aggression were both provided at the end of the class. Aggressive behaviors were identified as "risky" and "unnatural to being human, such as violence."

The other statistically significant change from the beginning to the end of the class involved a decrease in the presence of the norm of achievement/status. At the beginning of the class, men were defined as providers and protectors. An example of a typical response capturing this theme was: "Traditionally, I think of masculinity as . . 
. a preference for being the protector \& provider in a family." The majority of students presented this norm without qualification, implicitly suggesting that they endorsed it, while a minority framed this idea as being drawn from societal norms rather than their personal attitudes (e.g., "[Masculinity is] a script that contains the rules/roles by which a man must act. These rules traditionally consisted of . . great expectations of achievment $[$ sic $]$ and independance $[$ sic $] . ”)$. A handful of students also noted that men are expected to achieve career success or act as leaders. Post-class responses relating to achievement/status centered on power, and every participant framed it as a stereotype, role, or unattainable ideal. In other words, they acknowledged the norms while declining to endorse it. Thus, it appears that participants may have changed their attitudes toward the norm of achievement/status over the academic quarter. However, it is also possible that the class simply helped them articulate where these norms originate.

Two additional trends became evident while reviewing the data. The first of these was the idea that traditional masculinity is harmful, either to men or to everyone. While a few participants wrote responses to this effect at the beginning of the class, by the author's count about eleven referenced it at the end of the class. In response to the prompt "What is masculinity?" at post-class, one participant simply wrote "Bad for your health." Others echoed this sentiment. Apart from an explicit focus on health, traditional masculine norms were also called debilitating, limiting, and dysfunctional. Given that the class emphasized both physical and emotional harm associated with masculine role norms, particularly aggression and restrictive emotionality, it would 
seem that this concept became a salient aspect of respondents' beliefs about masculinity.

The other trend, which was present in roughly one fifth of the responses at each time point, was defining man or masculinity counter-normatively, either alone or in combination with more traditional norms. For several participants, this description took the form of noting that men can, or even should, be both masculine and feminine. Interestingly, this interpretation implies an acceptance of the idea that masculinity and femininity are accurate characterizations of behavior. In other words, masculinity and femininity are inherently different and probably binary. Thus, perhaps these students were interpreting the question in terms of what an ideal man is to them; one student included in her definition of "man" that "there is a man out there perfect for each of us." A few participants noted that norms were also becoming more progressive in society: "I also think that masculinity is changing- in 2005, media sources being [sic] to revere the "metrosexual" man. I think masculinity is beginning to encompass more and more characteristics."

Another interesting way participants described men/masculinity counternormatively was in regards to emotional expressiveness and being "loving" or secure in oneself. This idea was mentioned by about one third of respondents and was similarly prevalent at the beginning and end of the course. Often security took the form of freely expressing emotion, suggesting that participants are aware of and reject the male norm of restrictive emotionality: "To be strong and secure in yourself to be able to show tenderness and cry, without fear of others judging you, is a much stronger 
man than the "tough" guy who is masking their true self in order to fit societal expectations of a man.” This decision to reject the norm could explain why there were no differences in the presence of restrictive emotionality over time; presence of the norm does not necessarily indicate endorsement. These counter-normative concepts have been described in other examinations of masculine ideology (e.g., Gale, 1999; Hegleson, 1994). Designed to capture a variety of masculinities, including those positive attributes that are commonly neglected in quantitative measures of masculine ideology, one qualitative study discovered that many men value being a caring family man (Gale, 1999). This ideal could be viewed as an extension of the traditional male role of provider and head-of-household or as an acceptance of the traditionally feminine quality of nurturance. However, it cannot be captured by the MRNI and similar measures; the related norm of restrictive emotionality is similar but distinct. More research is needed to determine the nature of positive masculinities as well as the effect of gender education on such ideologies. Qualitative data, such as those collected in the present study, are an ideal format for this exploration.

In the present study, the quantitative and qualitative data offer unique advantages. The MRNI, while somewhat limited in scope, has good broad coverage of male role norms. It also has the advantage of consistently measuring valence; the instructions clearly asked for students' agreement with each statement. In contrast, students rarely mentioned more than one or two role norms in their definitions of "man/masculinity," and it was sometimes difficult to determine whether they intended to present norms as descriptive/societally prescriptive or whether they were personally 
endorsed. However, the qualitative format allowed students to comment on aspects of male gender roles beyond those represented in the MRNI. Qualitative data also provides some protection against demand characteristics, as previously discussed.

The findings of the qualitative data analysis in this study mirrored those of the quantitative data, providing converging evidence about the hypotheses. The decreased endorsement of the aggression subscale on the MRNI directly relates to the decreased prevalence of the norm in students" definitions of "man/masculinity." Additionally, the reduced prevalence of achievement/status in students' definitions mirrors the drop in endorsement of Factor 1 (which includes the conceptual dimension of achievement/status). While none of the other norms were significantly less present in responses at the end of the class, perhaps due to a lack of sufficient statistical power to detect change, the raw presence was either stable or decreased over time for homophobia, non-relational sex attitudes, restrictive emotionality, and self-reliance. Only avoidance of femininity was more commonly discussed at the end of the class, and in every instance it was framed in terms of social expectations rather than personal endorsement (e.g., "The level of masculinity is described by how well a man fits into the antifeminine role."). Thus, the qualitative data are largely consistent with the hypothesis that women would have more progressive male gender role attitudes after taking the course. 


\section{Study 2}

Study 2 examines potential selection effects in Study 1 by comparing pre-class attitudes toward male gender role norms from women in the elective masculinities class against those from women in a psychology course unrelated to gender (i.e., Research Methods in Psychology) that is required of all psychology majors at the university. Discovering pre-class differences, or selection effects (which have been found consistently in similar examinations of women's studies students), would suggest limited generalizability of the results. It could also suggest that students enrolling in the gender-related course were already on a different developmental trajectory in terms of their gender role attitudes and thus would be likely to display increasingly progressive attitudes over time regardless of the course content. If students begin the courses with different attitudes, it cannot be assumed that they would all respond similarly to the experience of a gender-focused class. Perhaps willingness or motivation to change is a necessary precursor for students to voluntarily elect to take gender-focused courses. On the one hand, taking a course with similarly motivated students could support personal growth and change. On the other hand, one could argue that students who are not attracted to gender-focused courses, perhaps because the class misaligns with their ideologies, would have the most to potentially gain from any attitude-changing effects (i.e., their attitudes would have more room to shift). In either case, awareness of these tendencies could inform academic requirements or the way instructors frame their classes to prospective students. 
Research Question 2. How representative are women electing to take a course on the psychology of men and masculinities compared to all female-identified psychology majors? That is, do women electing to take a course on the psychology of men and masculinities and women in a psychology research methods course required for all psychology majors have the same attitudes toward male gender role norms at the beginning of their respective courses?

Hypothesis 2. Past research has shown that students electing to complete WGS courses have a greater awareness of sexism and more egalitarian attitudes than other students (Stake \& Hoffmann, 2001). Thus, women in an elective psychology of men and masculinities class are expected have more progressive attitudes about male gender role norms than women in a psychology class not related to gender. I hypothesize that the pre-class MRNI subscale and total scores of women taking the psychology of men and masculinities course are lower than the pre-class scores of women in the research methods course.

\section{Method}

\section{Participants}

Participants included women in the winter 2011 Psychology of Men and Masculinities course as well as women in the fall 2013 psychology Research Methods course required of all psychology majors. For consistency across Studies 1 and 2, the sample in the masculinities class was restricted to the 19 women who completed both the pre- and post-class questionnaires, which represents $46.3 \%$ of all the women 
enrolled in the class $(N=41)$, although only pre-class data are examined in Study 3 . Further demographic data was not collected from women in this class.

In the Research Methods class, questionnaires were completed by nineteen $(86.4 \%)$ of the women enrolled $(N=22)$. Ages of the women in the Research Methods class ranged from $19-46(M=27.6, S D=9.5)$. Fourteen participants reported being White, and the remaining five were bi- or multi-racial. Fifteen were psychology majors, one was a psychology minor and social science major, and one participant each were planning to major in social science, health science, and molecular biology. It is notable that all but two of these women were focusing their studies on social sciences. While nine had previously taken a gender-focused course, none had previously taken the masculinities course also being examined in this study.

\section{Measures}

Women's attitudes toward men's gender role norms. Students who identified as women were asked to complete the Male Role Norms Inventory (MRNI; Levant et al., 1992), which evaluates attitudes toward male roles. This measure is described in Study 1.

\section{Procedure}

The method of data collection with the women in the winter 2011 Psychology of Men and Masculinities class is described in Study 1. Briefly, female-identified students completed the MRNI in class on the first day of class and again before the final exam. 
Students in the Research Methods course were recruited during the first two weeks of classes in fall 2013. The primary researcher and an undergraduate research assistant visited the classroom to explain the general content of the questionnaire and hand out a packet with the survey questions. Separate versions of the questionnaire were available for female- and male-identified participants. Female-identified students completed the MRNI and demographic questions. Participants were also asked to confirm that they had not previously taken the Psychology of Men and Masculinities course. No participants were excluded based on this criterion.

\section{Results}

The data consisted of total and subscale MRNI scores at the beginning of the Psychology of Men and Masculinities class and the Research Methods class, respectively. Means on the total MRNI scores were slightly lower for students in the Research Methods class $(M=2.29, S D=.36)$ than in the Masculinities class $(M=$ $2.39, S D=.35)$. Similarly, Research Methods students showed slightly less endorsement of self-reliance ( $\mathrm{SR} ; M=3.53, S D=.50)$, aggression (AG; $M=2.99, S D$ $=.82)$, and the MRNI's Factor $1(\mathrm{~F} 1 ; M=2.99, S D=.82)$ than students in the Masculinities class $\left(M_{S R}=3.57, S D_{S R}=.61 ; M_{A G}=3.15, S D_{A G}=.61 ; M_{F 1}=2.07, S D_{F 1}\right.$ $=.34)$.

To test whether pre-class MRNI scores differed significantly between femaleidentified students in the two different courses, independent-samples $t$-tests were performed comparing pre-class total and subscale MRNI scores across classes (see Table 6). Adjusting for the number of $t$-tests (four total) using the Bonferroni method, 
critical $p$ values were 0.0125 . There were no significant differences on any of the dimensions tested. Total MRNI scores did not differ between the Psychology of Men and Masculinities and the Research Methods class, $t(36)=.83, p=.41, d=.28$. Similarly, they did not differ on self-reliance, $t(33)=.20, p=.84, d=.07$, Factor 1 , $t(36)=.64, p=.53, d=.20$, or aggression, $t(35)=.66, p=.52, d=.22$. While $p$ values for the tests of the total MRNI and self-reliance subscale were slightly lower with the inclusion of item 21 , none of these tests were significant even with its inclusion. However, it is important to note that not only was the internal reliability low for the self-reliance subscale, as previously discussed, but achieved power was also unacceptably low for all tests (see Table 6), ranging from .06 to .14.

\section{Discussion}

Study 2 was designed to determine whether there were differences in the preclass male role norm endorsement between women completing an elective course on the Psychology of Men and Masculinities and those completing a psychology Research Methods course unrelated to gender. Past research has found that students completing WGS classes have significantly more egalitarian attitudes and a greater awareness of sexism and discrimination before taking the class than do students choosing to take a non-WGS class (Stake \& Hoffmann, 2001). Thus, it was hypothesized that women in the Masculinities class would have more progressive attitudes than those in Research Methods. This hypothesis was not supported; there were no significant differences between the classes on either the total MRNI scores or subscale scores. 
The sample size of these tests presents an important concern with the interpretability of the results. Because the tests were underpowered, the chances of detecting a true difference in the mean scores would have been extremely low. It is possible that larger samples would have returned significant differences. An examination of the descriptive statistics of both courses, however, shows that Hypothesis 3 would likely remain unsupported. Students in the Research Methods class actually displayed slightly less endorsement of traditional male role norms than those in the Masculinities class.

The low internal reliability of the self-reliance subscale also may have contributed to lack of significant differences between the two classes' endorsement of masculine role norms. Specifically, the subscale Cronbach's alpha was very low in the Research Methods course (-.10) and low in the Masculinities course (.52). Since low reliabilities generally mean higher error variances, which could muddy any differences in true variance between the two samples, it is extremely unlikely that the $t$-test could have been significant. Thus, this particular test would have to be regarded with caution even if the achieved power had been acceptable.

While Hypothesis 2 was not supported, and readers should keep in mind the issues of statistical power in Study 2, the lack of a significant difference between the two classes' endorsement of male role norms could indicate that there were no selection effects for existing male role attitudes in Study 1. Selection issues are of particular concern in this study because of the possibility that students who choose to take the masculinities course are on a different attitudinal trajectory than those who do 
not. If students in the masculinities course have a change in attitudes over time, then it is possible that other students (namely, those who are not electing to take such a course) would display the same change in attitudes if they were exposed to the same experience.

Another important consideration involves the time difference between the administrations of the MRNI in each class. The Research Methods course completed the measure in 2013, about two years after the Masculinities class. As described earlier, past research has shown that gender role attitudes generally become more egalitarian with each successive generation (Brooks \& Bolzendahl, 2004) as well as over the course of the lifespan (Fan \& Marini, 2000). Thus, it is possible that students in the Research Methods course would have had more traditional attitudes than were observed in the present study had they been surveyed at the same time as the Masculinities class. This hypothesized impact of time would explain why the results of Study 2 failed to support prior research demonstrating greater egalitarian attitudes among students choosing to complete a WGS class (Stake \& Rose, 1994).

However, research has found "considerable stability in gender-role attitudes throughout the period of transition of adulthood" (Fan \& Marini, 2000, p. 277), including three- and five-year intervals. The same study concluded that, “. . . genderrole attitude change is not a function of maturation or increased exposure to general societal influences with age but rather a function of specific socializing experiences during the transition to adulthood" (p. 277). While education was found to increase egalitarianism in some populations, this trend did not hold in women progressing from 
ages $22-25$ to $27-30$, the sample most equivalent to women in the present study. In other words, the trend toward increasingly egalitarian gender role attitudes seems to be mainly observable over a matter of decades rather than a few years (i.e., the difference in data collection between the Masculinities and Research Methods classes). While the non-random sample in the present research could potentially be vulnerable to systematic differences in other characteristics that impact gender role attitudes (e.g., marriage, parenthood, workforce entry), there is no evidence to either support or refute this possibility.

Related to the concept of predisposition or readiness for attitude change is the question of the underlying source of gender role attitudes. Do the gendered expectations imposed upon oneself, for example, in turn influence the expectations one holds for others? Study 3 delves into this relatively unexplored area of research by considering the existence of a common gender attitude system underlying both women's experiences of stress from feminine role norms and their attitudes toward male role norms. 


\section{Study 3}

Study 3 examines the relationship between attitudes toward male gender role norms and GRS in women completing the Psychology of Men and Masculinities class in the fall of 2012. A significant correlation between these constructs would support the existence of a common factor underlying gender pressures for self and gender expectations of others. For example, a belief in the innateness of gender differences could create pressure to conform to the traditional roles of one's gender while simultaneously holding others to the same kinds of expectations.

Research Question 3. What is the relationship between women's gender role stress and attitudes toward male roles?

Hypothesis 3. Past research has shown a negative relationship between men's gender role conflict and progressive attitudes toward women's roles. However, the equivalent relationship has never been examined in women. I hypothesize that women's gender role stress, measured using the FGRS, positively correlates with endorsement of traditional male roles, assessed with the MRNI.

\section{Method}

\section{Participants}

Participants were women taking the Psychology of Men and Masculinities course in the fall of 2012 . Thirty-two women, or $91.4 \%$ of the 35 women enrolled in the course at any point in the quarter, participated at the beginning of the academic quarter. Fourteen (40\%) participated at the end of the quarter, although three women did not attend the final exam session during which the questionnaires were 
administered, and twelve (34.3\%) participated at both time points. To avoid capturing any unintentional impact of course completion on either GRS or male role attitudes, this study examines only pre-class data from all 32 women who completed the questionnaire at the beginning of the course.

Of these women, ages ranged from nineteen to $57(M=25.8, S D=8.8)$. The majority of participants were White $(n=22)$, but five identified as biracial, two as Black, two as Hispanic/Latino, and one as Asian/Pacific Islander. Most were also heterosexual $(n=26)$, although six participants identified with other sexual orientations. Twenty were majoring in psychology, three in women's studies, and nine in other domains.

\section{Measures}

Women's attitudes toward men's roles. Students who identified as women were asked to complete the Male Role Norms Inventory (MRNI; Levant et al., 1992), which evaluates attitudes toward male roles. This measure is described in Study 1 .

Women's gender role stress. Women's gender role stress was measured using Gillespie and Eisler's (1992) Feminine Gender Role Stress (FGRS) scale. The 39-item FGRS scale asks women to imagine a hypothetical situation and rate the extent to which they would find it stressful (from $0=$ not at all stressful to $5=$ extremely stressful). Items correspond to one of each of the five theorized components of gender role stress: fear of unemotional relationships (e.g., "Feeling pressured to engage in sexual activity"), fear of physical unattractiveness (e.g., "Being perceived by others as overweight"), fear of victimization (e.g., "Feeling that you are being 
followed by someone"), fear of behaving unassertively (e.g., "Negotiating the price of car repairs"), and fear of not being nurturant (e.g., "Having someone else raise your children"). Cronbach's alpha for each subscale in the original sample of undergraduate students ranged from .73 to .83 , and two-week test-retest reliability was .82 (Gillespie \& Eisler, 1992).

Cronbach's alpha for the total scale was very good in the current sample of women taking Psychology of Men and Masculinities: .93. While the FGRS is not widely used outside of the counseling and clinical literature, there is good preliminary evidence of its convergent and discriminant validity. It has a moderate correlation with a measure of small, daily stressors and small but significant correlations with femininity and depression symptomology (Gillespie \& Eisler, 1992).

The generalizability of the FGRS, however, is questionable; the items were generated based on the responses of female undergraduates at an Eastern university in the United States, and no sample characteristics besides age were reported. The FGRS appears to be based on expectations of femininity within White, middle-class American culture and might not be equally valid in all respondents. For example, gaining weight or acting assertively could hold different meanings, and thus cause different levels of stress, in women of different ethnicities or regional cultures. Additionally, certain items, particularly some items in the "fear of unemotional relationships" subscale, appear to have questionable construct validity. While about half the items focus on promiscuity, several others inquire about potentially dangerous sexual situations. Items such as "Feeling pressured to engage in sexual activity" and 
"Having to deal with unwanted sexual advances" are qualitatively different than "Being considered promiscuous." The former assesses stress from the very real threat of sexual violence, while the latter measures stress from the expectation of female chastity. Even the most sexually liberated woman can worry about being the target of sexual violence, which has no inherent link to her feelings about relationships. The fact that this subscale includes two distinct constructs (i.e., sexual threat and the expectation of chastity) should subject conclusions based on this subscale to special scrutiny. For example, a participant who fears being sexually assaulted or coerced but enjoys casual sex could have a score suggesting that she finds "unemotional relationships" somewhat stressful when in fact she is not at all stressed by sex outside of an emotionally intimate relationship. It would be difficult to interpret significant findings with this subscale without examining responses to the individual items; what would it really mean if this subscale were correlated with attitudes toward male role norms? Perhaps women who fear sexual assault, for example, believe that men are innately driven to seek sexual gratification without emotional involvement.

\section{Procedure}

The 2012 Psychology of Men and Masculinity class studied content almost identical to previous iterations of the course, but data were collected online using Qualtrics survey software rather than with paper questionnaires distributed in class. A few days before the first class session, the professor emailed students a brief description of the study and a link to an online questionnaire. Students were reminded during the first week of classes to complete the questionnaire online if they planned to 
participate. The questionnaire began with an informed consent page (see Appendix A) explaining the general purpose of the study. Participants were then asked to provide the name of their favorite pet so that their pre- and post-class responses could be matched while still protecting their personal identity. After identifying their gender, participants were automatically directed to the female or male version of the study. Women completed the Feminine Gender Role Stress Scale (Gillespie \& Eisler, 1992) and the revised Male Role Norms Inventory (Levant et al., 1992). Men completed the Gender Role Conflict Scale (GRCS; O’Neil, 1986) and the Attitudes Toward Women Scale (Spence \& Helmreich, 1972). Participants who were eighteen or older and who reported some sexual activity in the last ten weeks also filled out the New Sexual Satisfaction Scale (Stulhofer, Busko, \& Brouillard, 2010). Lastly, all participants supplied demographic information (e.g., age, year in college, academic major). Participants were thanked for their time and effort, debriefed (see Appendix C), and reminded that they would be contacted through the class roster at the end of the academic quarter to complete the follow-up questionnaire. Pre-class data were collected between September 21 and 29, 2012.

The follow-up questionnaire link was emailed on the last day of class (with several email reminders in the week following). Although follow-up data were collected before final course grades were submitted, participants were reminded in the consent form that the data would be collected anonymously and would not affect their course performance in any way. After confirming their consent to participate, students again provided the name of their favorite pet and completed the questionnaire. The 
content of the questionnaire was the same as the pre-class version except for an additional question about number of absences from class. When the questionnaire was finished, participants were thanked and fully debriefed (see Appendix D). Post-class data were collected between November 28 and December 7, 2012.

\section{Results}

To examine the relationship between women's gender role stress and traditional attitudes toward male role norms, Pearson correlation coefficients were computed between mean total scores on the FGRS and the MRNI total and subscale scores (see Table 7). All correlations were small to moderate and nonsignificant. Total FGRS scores correlated weakly with MRNI total scores, $r(32)=.20, p=.27$, Factor $1, r(32)=.20, p=.28$, the self-reliance subscale, $r(32)=-.08, p=.66$, and the aggression subscale, $r(32)=.30, p=.09$. However, achieved power, assuming that the sample parameters accurately represented those in the population, was found to be unacceptably low: .07 for aggression, .20 for both the MRNI total and Factor 1, and .39 for self-reliance. As would be expected, all components of the MRNI (including the total score) were moderately to highly intercorrelated.

\section{Discussion}

Study 3 tested the hypothesis that female students' endorsement of traditional male role norms would positively correlate with their feminine gender role stress. This hypothesis was not supported by the data. However, most of the correlations between the MRNI and FGRS were positive and weak to moderate, though not 
significant, and all tests were underpowered. Only one correlation was slightly negative: that between the self-reliance subscale of the MRNI and the FGRS.

While not significant, there was a trending moderate correlation between the FGRS and the MRNI aggression subscale. Some of this relationship could be due to items that are similar across the FGRS and MRNI. For example, the MRNI aggression subscale has the item "Men should get up to investigate if there is a strange noise in the house at night," and the FGRS asks about stress in regards to "hearing a strange noise while you are at home alone." However, this kind of conspicuous similarity between items in the two scales is uncommon. More likely is the possibility that they are tapping into underlying beliefs about the nature of men and women. The FGRS has several items, across various subscales, which reference traditional gender roles within a romantic relationship. While the FGRS does not specify the sex of the romantic partner in question, it is likely that most women were imagining a heterosexual relationship ( $81.3 \%$ of participants who indicated a sexual orientation identified as straight/heterosexual). A potential connection between this theme and the male role norm of aggression would be a woman's stress from "having a weak, incompetent spouse." Valuing the male norm of aggression could tap into a desire or expectation for men to serve as protectors. The fact that aggression had a trending relationship with the FGRS despite the underpowered test suggests that this relationship would be worth exploring in future research.

The surprising absence of even a weak correlation between the FGRS and the self-reliance subscale could be due to insufficient power or the self-reliance scale's 
somewhat low internal consistency (Cronbach's alpha $=.65)$. Results could be different if the study were conducted using an updated version of the MRNI. Because of both conceptual issues and limited statistical power in the present study, more research is needed to examine and clarify the existence of the potential relationship between women's GRS and their male role attitudes. 


\section{General Discussion}

The present research was intended to evaluate the possible impact of an undergraduate Psychology of Men and Masculinities class on women's male role attitudes. Specifically, it was expected that students' attitudes toward male role norms would be more progressive at the end of the class than at the beginning, a hypothesis that was largely supported by both the quantitative and qualitative data. One concern is the possibility that students electing to take the masculinities course have more progressive attitudes toward male role norms than the general population of students in psychology courses, even before the class began. Students could be differentially selecting into the course based on their preexisting attitudes about gender role norms. This difference could mean that any effect of the course on gender role attitudes is limited to students already on an attitudinal trajectory of change, suggesting that the course's impact has limited generalizability. The findings of this research provided no evidence that students in the masculinities class have different pre-class male role norm attitudes than students in a psychology research methods course. However, small sample sizes resulted in limited statistical power to detect differences between students in the two classes. Consequently, the lack of evidence for differences should not be viewed as strong evidence that the changes are representative of other students' responses. Another goal of this research was to assess the relationship between female students' endorsement of traditional male role attitudes and their own feminine gender role stress. Somewhat surprisingly, no evidence of a relationship was found. However, this study also suffered from underpowered statistical tests, which 
considerably limits confidence in the implications of this finding. Larger samples would provide a more reasonable ability to detect a relationship among these constructs and differences between the groups of students.

The finding that women displayed increasingly progressive attitudes toward male role norms after completing the masculinities class is in line with past research, which has demonstrated the ability of women's studies courses to impact gender attitudes (e.g., Stake \& Hoffman, 2001; Stake \& Rose, 1994). Past research has shown that students completing WGS classes, specifically those focused on women, tend to have increased egalitarian attitudes, awareness of sexism and other kinds of discrimination, and increased participation in social activism (Stake \& Hoffman, 2001). Some of these changes have also been demonstrated to last at least nine months from the completion of the course (Stake \& Rose, 1994). However, to the author's best knowledge, this is the first study to demonstrate change in gender role attitudes in a class focused on men and masculinity. Furthermore, not only was the course in this research focused on men and masculinity—rather than women and femininity_but the measures also assessed change in gender role attitudes specifically toward male role norms.

This research also discovered that women's definitions of "man" and "masculinity" included fewer instances of certain male role norms at the end of the class than at the beginning, specifically the norms of aggression and achievement/status. While there was no significant change in the prevalence of the other five male role norms examined, there was also low statistical power to detect 
these changes. The finding that two role norms were less prevalent over time is congruent with the students' decreased endorsement of male role norms on the MRNI. Also supporting this trend was the discovery that post-class definitions of "man/masculinity" were far more likely than pre-class definitions to describe traditional masculinity as negative. At the end of the class, about one-third of respondents argued that traditional masculinity was harmful or limiting. This new recognition of traditional masculinity as harmful could be one reason why aggression and achievement/status were less common in post-class definitions; this perspective would be incongruent with role norm endorsement.

A logical next step in this line of research would be to determine whether classes focused on masculinities also change women's and men's attitudes toward female gender roles. To interpret any potential "crossover effects" (i.e., changes in attitudes toward the gender that is not the primary focus of the course), it would be useful to better articulate the curricular content of gender-focused courses. Currently, the distinctiveness of the content in men's studies classes in comparison to traditional WGS classes is unknown. The majority of professors who teach psychology of men courses (74\%) indicate that they incorporate content on women's issues into the course (O’Neil \& Renzulli, 2013a). However, the extent to which WGS classes focused on women include material on issues relevant specifically to men is unknown. While men's and women's issues overlap, as both genders experience gendered pressures, women's studies classes probably devote relatively less attention to the nature and effects of male role expectations. For example, a discussion of work in a 
women's studies course might focus on discrimination and the balance between work and family, whereas a men's studies course might discuss how the breadwinner role causes stress. Of course, most topics share some relevance for both genders (e.g., men also experience work/family conflict). In other words, whether content is considered “women's issues” or “men's issues” is probably just a matter of framing.

In addition to course content, other potential moderating variables of attitude change include the instructor's gender and the teaching of gender as non-binary. For example, perhaps presenting gender as multidimensional, as in Bem's (1974) model of intersecting masculinity and femininity, would change the way students conceptualize gender and consequently foster acceptance of more varied gender expressions. Or, perhaps students are more likely to internalize attitudes they see expressed by a progressive same-gender instructor through stronger identification. Social learning theory would predict that taking a class with a gender counter-stereotypic instructor could also increase progressive gender attitudes through observation and modeling. Past research on racial attitudes would support this hypothesized outcome; there is evidence that exposure to a non-stereotypic target can reduce stereotypic perceptions of members of the target group (Vescio, Sechrist, \& Paolucci, 2003). More research on course content is needed to identify potential influences on attitude change, especially for students whose gender is not the focus of the class.

The change in women's male role attitudes observed after taking the masculinities class has relevance to their lives outside of the classroom. Women's attitudes toward male role norms have been neglected in the psychological literature, 
especially compared to research on men's attitudes toward women's roles.

Additionally, the vast majority of past work on this topic has been limited to the context of heterosexual romantic relationships. Women's endorsement of traditional male role norms is associated with negative attitudes toward condom use (Smith, 1996, as cited in Levant \& Richmond, 2007); lower relationship satisfaction (Mcgraw, 2001); their male partners' endorsement of traditional male role norms as well as their perceived authority, dominance, and intrusiveness behaviors (Mcgraw, 2001); and beliefs about men's parenting roles (Bonney, Kelley, \& Levant, 1999). A significant majority of female students in the 2012 masculinities class indicated that they were in a relationship at the time of the study (the relevant data was not available for the 2011 class). Consequently, there is evidence that the course's impact on their beliefs about male role norms is directly relevant to many of their lives. Considering the likelihood that the female students in this class will eventually engage in sex, romantic relationships, or parenting with men, the outcomes described above will eventually become relevant to nearly every female student in the class (only one female student indicated an exclusively homosexual orientation). While less explored in the literature, women's attitudes toward male roles also have relevance outside of the context of heterosexual romantic relationships. These attitudes could influence how women interact with male coworkers, supervisors, subordinates; peers in educational contexts; friends; and even strangers (e.g., they might expect dangerous or benevolent behavior). 
One weakness in past studies linking the endorsement of traditional male role norms and negative health and interpersonal relationships involves the common use of correlational designs. Thus, it is uncertain whether endorsement of traditional male role attitudes caused these outcomes and whether the change in women's male role attitudes would be expected to correspondingly result in improved relationship outcomes. As discussed before, gender is a reciprocal process. People both create or reproduce gendered expectations and experience pressure to follow those expectations. Women's interactions with men (including the health, relationship, and parenting outcomes described above) could also be a causal factor in changing male role attitudes. Research has found, for example, that young women exhibit decreased egalitarian attitudes after marriage (Fan \& Marini, 2000). As discussed in the introductory section of the present research, egalitarianism involves attitudes toward both men's and women's roles, usually in a comparative context. Thus, it is unknown how or whether these women's attitudes toward male gender role attitudes in particular shifted.

Women's attitudes toward male role norms also have importance beyond their own personal experiences. While it is currently unknown whether or how women's male role norm attitudes influence the same attitudes in men, a culture in which women expect traditional masculinity seems likely to foster similar attitudes in men. Further, men's endorsement of traditional male role norms is related to a variety of negative intrapersonal and interpersonal outcomes such as depressive symptoms and suicide (Houle et al., 2008; Shepard, 2002), physical and sexual aggression (Cohn \& 
Zeichner, 2006; Rando et al., 1998), intimate partner violence (Moor \& Stuart, 2005;

Schwartz et al., 2005), and relationship problems with romantic partners (e.g., Campbell \& Snow, 1992). Thus, women's increasingly progressive male role norm attitudes might indirectly improve men's health and relational outcomes and behaviors.

When considering the potential for individuals' increasingly progressive gender role attitudes to result in improved health and relational outcomes, one must consider who is likely to experience this attitudinal change. The present research examined attitudinal change in a sample of self-selected students completing a psychology course, which is already a unique population. The field of psychology has been criticized for conducting research with samples that are different than the "average" world population in terms of culture, education, wealth, and societal attributes (Henrich, Heine, \& Norenzayan, 2010). While the present study does not intend to be applicable to the universe of all students, there are theoretical reasons to consider the possibility that our sample is unique, particularly in comparison to students who realistically have access to the masculinities class. It was expected that students taking the masculinities class would have more progressive pre-class male role norm attitudes than students in a general psychology course. Such a difference could indicate that students enrolled in the course because of their existing role norm attitudes, which would raise questions about the role of the course in any change in their gender role norms. This study did not find statistically significant differences, however, between the pre-class male role attitudes of students in the different classes. 
As previously discussed, however, small sample sizes limited the statistical power to detect any true differences that might have existed.

The failure to find a difference in pre-existing attitudes about gender role norms between students enrolled and not enrolled in gender relevant courses is somewhat incongruent with prior research. Specifically, past research has found that students choosing to take a WGS class had more egalitarian attitudes toward women than those in a non-WGS class, even at the beginning of the course (Stake \& Hoffman, 2001). One possible explanation for this discrepancy involves the comparison groups being sampled. In Stake and Hoffman (2001), the classes sampled were divided between professors teaching in the social sciences and in the humanities. The comparison sample in the present study was an upper-level psychology course, like the psychology of men and masculinities class. Data from the 2012 masculinities class indicated that $62.5 \%(n=20)$ of female students were majoring in psychology, and $75 \%(n=24)$ were majoring in a social science. Similarly, $78.9 \%(n=15)$ of women in the Research Methods class were psychology majors, and $89.5 \%(n=17)$ were in a social science field. Past research has found some differences in male role attitudes based on academic major. For example, male university students majoring in traditionally masculine subjects (e.g., computer science, engineering) have higher endorsement of the male role norms of antifemininity, restrictive emotionality, and homophobia than men in female-dominated subjects (e.g., nursing, counseling; Jome \& Tokar, 1998). Another study found that among students taking one of two social work courses, the students with the most egalitarian attitudes were those majoring in 
social work, followed by psychology majors, undecided students, and criminal justice majors (Black, 1994). Thus, perhaps the failure to find differences between the gender-focused class and the comparison class was due to the relative similarity in the courses being sampled. It seems clear that students in both the Psychology of Men and Masculinities course and psychology Research Methods class would at least share some interest in psychology. It is more accurate to say, then, that the present study failed to find evidence of selection effects among students studying the discipline of psychology, perhaps because of limited statistical power.

Another surprising result was the lack of a relationship between women's endorsement of male role norms and their feminine gender role stress. Not only was there was no significant association between these constructs, but the correlations were of a small to moderate magnitude. As previously discussed, however, these inferential tests lacked sufficient statistical power to detect a true association. Problems with particular items in the FGRS, also previously discussed, are another possible explanation for this outcome. The FGRS was designed with stress and health outcomes in mind. Thus, the survey items may not necessarily be representative of the typical gendered stressors experienced by women in the present sample. For example, five items ask about situations with children (e.g., "Returning to work soon after your child is born"), and another five reference having an intimate partner (e.g., "Your mate is unemployed and cannot find a job"). While there is no doubt variation in the experiences of individual students, it is likely that many have not had experiences with serious, long-term relationships or child rearing and would thus be responding to these 
hypothetical scenarios without a good frame of reference. The students in this sample are, on average, younger than the population from which they were selected into the university. The mean age of female students in the 2012 Psychology of Men and Masculinities class was 25.8 years, nearly identical to the average age of all students taking classes in the psychology department $(M=26$; E. Mankowski, personal communication, December 12, 2014).

It is interesting that the present study found no evidence of a relationship between the FGRS and MRNI whereas prior research has found that a correlation between men's GRC and attitudes toward women's egalitarian roles (Blazina \& Watkins, 2000; Robinson \& Schwartz, 2004). However, these correlations found previously were of a small enough magnitude that they would have been undetectable with the sample size of the present study. The null results, then, could simply be a result of insufficient statistical power.

Alternatively, this incongruity could relate to the qualitatively different nature of men's and women's gendered stress. Men's rejection of femininity, which is part of GRC, has been hypothesized to underlie their negative attitudes toward egalitarian roles (Blazina \& Watkins, 2000; O’Neil, 1986). However, women's GRS does not include the fear of being seen as masculine, perhaps because masculine characteristics are valued more highly than feminine ones. GRS in women, then, lacks this inherent link to their attitudes toward male roles. However, it is also possible that the failure of the present study to find this equivalent relationship in women is due to measurement differences. Specifically, Robinson and Schwartz (2004) used the Attitudes Toward 
Women Scale (AWS), which is really a measure of egalitarianism rather than of women's roles in general (Spence \& Helmreich, 1972). Similarly, the outdated scale used by Blazina and Watkins (2000) to assess attitudes toward women has been described as "a measure of sexist or authoritarian attitudes toward women" (Royce \& Christiansen, 1977, p. 294). Really, then, these previous studies established a link between men's GRC and their attitudes toward egalitarianism, not toward women's actual role norms.

The present research measured male role norm attitudes, which is related to but distinct from gender egalitarianism. Egalitarianism as measured by the Attitudes Toward Women Scale contains primarily gender-comparative items - and some implicit heteronormativity — making it nonequivalent to the MRNI. For example, the AWS includes items such as, "It is ridiculous for a woman to run a locomotive and for a man to darn socks" and "Women earning as much as their dates should bear equally the expense when they go out together," which, when surrounded by items that explicitly compare men and women, implies that the woman in question is dating a man. Thus, the AWS is partially measuring attitudes toward men's roles, which would logically relate to men's expectations for themselves and thus their experience of GRC. In contrast, the MRNI only references the male gender. Even those items of the MRNI that ask about sexual behavior leave the gender of the sexual partner(s) ambiguous. It is possible, then, that the correlation between GRC and egalitarianism in studies such as Robinson and Schwartz (2004) is a result of this conceptual contamination. Perhaps if the present study had compared women's GRS to 
egalitarianism rather than male role attitudes, the results would have mirrored those found in previous research.

The lack of a significant correlation between the FGRS and MRNI is not necessarily incongruent with prior research. A few different latent relationships could explain this disconnect. Firstly, it is possible that women have different attitudes toward the role norms of men and women. Traditional masculinity and femininity are distinct, not opposites (although masculinity includes the element of antifemininity), so endorsement of one is not necessarily related to endorsement of the other. For example, it would be possible for a woman to strongly believe that men should fulfill their traditional roles, but not that women should fulfill theirs (or vice versa). If masculine and feminine ideologies were not connected through an integrated gender ideology, attitudes toward male role norms would not necessarily correlate with women's GRS. However, research has shown that attitudes toward female role norms are correlated with attitudes toward male role norms in both male and female samples (Levant, Richmond, Cook, House, \& Aupont, 2007a). Correlations between the subscales of the measures ranged from .31 to .84 in women and from .40 to .85 in men, suggesting the existence of an underlying dimension of gender ideology.

Assuming that there truly is no relationship between women's GRS and male role attitudes, a more likely explanation for the present findings, then, is that women's gender role stress is not predicated on their attitudes toward female role norms. That is, a woman may feel pressure to fulfill the expectations of her gender regardless of the degree to which she endorses those expectations. More research is needed to 
determine whether and how women's attitudes toward the role norms of their own gender relate to the gendered stressors they experience.

\section{Limitations}

As with all quasi-experimental designs, it is important to acknowledge that significant changes in concepts or attitudes over time could be caused by something other than completion of the Psychology of Men and Masculinities course. Perhaps historical effects, such as highly publicized issues in the political realm, would cause students to reexamine and change their attitudes. Or, maybe certain life experiences common to undergraduate education (e.g., exposure to peers' differing perspectives, career experiences, and interactions with the other sex) challenged students' existing attitudes. It is also possible that other classes, formally relating to gender or not, impacted students' attitudes. However, this potential confound is an inescapable aspect of the naturalistic design. There is more to the undergraduate experience than pure academics; classes do not exist in a vacuum. Course material can provide students with new ideas about their life outside of the classroom. While the present study cannot control for such sources of unexplained variance, their inclusion could be viewed positively as realism.

Another set of potential limitations to this study involves the measures. Firstly, self-report measures are notoriously vulnerable to motivations including socially desirability and being a "good participant" (i.e., providing the answers seemingly desired by the researcher). The present research attempted to mitigate experimenter effects by reducing participant identifiability on the quantitative 
questionnaire, but it is possible that students still felt compelled to answer in a particular way. The complementary use of qualitative responses, which are openended, would require more mental effort to manipulate. The content of the pre- and post-class definitions were often similar within participants, suggesting that students did not feel particularly pressured to respond in a certain way (e.g., to please the professor). Those who originally described men in biological terms tended to do so at the end of the class as well. Similarly, there were many students who entered the class with a sophisticated awareness of gender issues and the distinction between biological sex and gender; these answers also generally stayed the same.

The significant reduction over time in the presence of the norms of aggression and achievement/status in the qualitative responses mirrors the decreased endorsement of traditional male role norms on the MRNI, supporting the validity of the quantitative data. However, these definitions are not a perfect corollary to the MRNI; the prevalence of norms could be interpreted in terms of endorsement or salience. This problem with measurement validity comes from the phrasing of the open-ended questions.

Specifically, it is unclear whether the questions are soliciting the participants' own prescriptive beliefs or, rather, perceived societal prescriptions or descriptions. Some students described what appeared to be their ideal man, some responded with their interpretation of social norms, and others attempted to describe social norms while also explaining how their personal ideals differed. Still others answered the question reflexively, such as the student who defined masculinity as "A term used to 
describe what it mean to be a "man," male [attitudes], the experience of being male." The meaning of the question "What is a man?" was particularly confusing for some students. At the post-class, one student wrote, “I don't know if we are talking about sex or gender." Many students attempted to differentiate between the two possible interpretations in their answers. The absence of change in the other five male role norms that were coded, then, might be explained by differences in participants' interpretations of the questions. Assuming that the class did not change students' perceptions of social norms, such as by making them consciously aware of implicit homophobia, the prevalence of norms would have stayed constant over time in the definitions of students who defined "man/masculinity" with descriptive or socially prescriptive rather than personally endorsed norms.

While the qualitative questions were designed to be open to interpretation to stimulate internal reflection, challenges in coding (i.e., the inability to perfectly distinguish between students' personally-held beliefs and those they perceive as normative or prescriptive in society) makes it difficult to generalize across students. Responses probably would have been different if students had been asked, "What is a man/masculinity to you?" or "In your opinion, what should define a man/masculinity?" Students could also be asked to detail descriptive or prescriptive social norms and compare their own ideals. Clarifying the questions could improve the richness and interpretability of data in future studies.

Certain aspects of the individual quantitative measures (i.e., the MRNI and FGRS) also raise concerns about their validity. As previously discussed, the MRNI 
subscales had inconsistent and often unacceptable reliabilities across samples. Closer examination of the fit statistics revealed that particular items had inconsistently poor or acceptable fit across the samples. While one item was removed to improve reliability before analyses were conducted (i.e., MRNI item 21), poor or borderline internal reliabilities would make it more difficult to uncover significant results. Issues with the factor structure of the original MRNI, the version administered in the present study, also complicate the interpretation of significant changes in participants' scores. While there were seven hypothesized scales, the original scale validation found support for a three-factor structure. Thus, the present study only examined change in the total scale; the self-reliance and aggression subscales, respectively; and the third subscale, which includes avoidance of femininity, homophobia, achievement/status, attitudes toward sexuality, and restrictive emotionality. The practical meaning of the self-reliance and aggression subscales are straightforward, as they are named constructs in themselves, but the third factor combines a number of male role norms that are not necessarily conceptually related. Thus, the significant decrease in scores on this subscale can only be interpreted as a general decrease in various male role norms. Post-hoc tests were conducted on the norms included in this subscale, but they were purely exploratory. Many of these individual norms did not demonstrate internal reliability, which would be expected given the known factor structure.

As it has been noted, the MRNI has undergone several revisions because of issues with internal reliability, factor structure, and content validity (including the modern relevance of certain items). Besides division of the original MRNI's Factor 1 
into different dimensions, the most relevant change in regards to the present study involves the content of the self-reliance subscale. In their report of the validation of the revised MRNI, the authors wrote, "the original Self-Reliance subscale did not capture the extreme degree of self-reliance that is normative for men (e.g., "A man should be able to perform his job even if he is physically ill or hurt")" (Levant et al., 2007b, p. 87). There are also several new items assessing physical work performance abilities. In contrast, the items in the original scale focus on decision-making and being realistic. Thus, results regarding self-reliance in the present study are not directly comparable to studies using later versions of the MRNI. Also important to note, but not as concerning for the present study, are conceptual changes in the achievement/status subscale. This subscale was re-conceptualized as "dominance." The items in the updated scale focus purely on leadership, especially in the work world, and abandon items focusing on work-life conflict and self-presentation (e.g., saving face or displaying status symbols). To improve consistency and statistical power, it is recommended that future research on masculine ideology utilize the updated versions of the MRNI.

The FGRS also has potentially problematic items, as discussed in the Method section of Study 3. Inclusion of these items has implications for the interpretation of results in the present study. While some items seemingly capture the kind of traditional gender role ideology that is hypothesized to underlie women's male role norm endorsement, others have questionable relevance. The fear of victimization subscale, in particular, would not necessarily be expected to relate to one's attitudes 
toward male roles. Fearing harm from others, regardless of their gender, does not mean that one believes men should be aggressive or highly sexual. Neither would it indicate that one believes women should be helpless or fearful. This distinction between perceived norm and prescribed norm is a major limitation in the interpretation of Study 3's results. Simply being aware of traditional social norms could cause a woman to feel gender role stress even if she personally rejects them. The failure to find a correlation between the FGRS and MRNI could be caused by this discrepancy between experience and ideals. Conversely, the presence of such a positive correlation would suggest that experiencing feminine gender role stress is related to endorsement of traditional male and female role norms on some level. Because of the limited statistical power in the present study, more research is needed to make firm conclusions about this possible connection.

Readers hoping to generalize the results of this research to other populations should be aware of the particular demographic characteristics of the participants. The sample primarily consists of current psychology students, many of whom were planning to major in psychology. The university at which the data were collected is known to have a relatively high proportion of nontraditional and returning students (PSU OIRP, 2013), and it is located in a primarily White, racially homogenous region of the United States (U.S. Census Bureau, 2014). Past research has shown that women and younger people generally have lower endorsement of traditional attitudes toward masculine roles (Levant \& Richmond, 2007). Additionally, while European Americans have been found to have lower endorsement of male role norms compared 
to African Americans, geographical location within the U.S. (Southern/rural versus Northern/urban) moderates this relationship (Levant, Majors, \& Kelley, 1998). Floor effects on the MRNI, which was a concern, were not present in the data. However, the potential impact of the Psychology of Men and Masculinities class in other populations, if it could be delivered exactly the same as it was in the present study, is unknown. Populations with more traditional male role attitudes might be less amenable to the idea of taking the course or might show more reactance to the course content. In other words, people with strongly-held traditional gender role attitudes could feel threatened by the progressive course material and reinforce their preexisting attitudes. Some research has suggested that reactance may vary by age, gender, and ethnicity (e.g., Woller, Buboltz, \& Loveland, 2007). Thus, it is possible that the female and mostly White population studied in the present research may have been unusually likely to demonstrate attitudinal change as a result of taking the masculinities course.

Response rates are another factor that could threaten the validity of the analyses in this paper. They were relatively high for the qualitative data $(78 \%$ of women enrolled in the course at any time). For the quantitative data, they ranged from $46.3 \%$ of all women enrolled in Study 1 to $91.4 \%$ in Study 3. However, the total enrollment numbers include students who dropped the class and joined the class after the first day and thus were unable to complete the pre-class questionnaire. Taking these factors into consideration, the participants included in this study appear to be generally representative of those students who attended class regularly and completed 
the assignments. Nevertheless, there likely remained influences of self-selection regarding both course completion and questionnaire completion. Students choosing to enroll and remain in the men and masculinities class, as well as take the time to complete the questionnaire outside of class in Study 3, might have had a particular and unique investment in gender-related issues.

The most serious limitation of the present research is the small size of the samples in each study, which restricted the power of the inferential statistical tests. In other words, the chances of positively identifying a real difference were low, resulting in an increased possibility of Type 2 errors. Besides possible Type 2 errors, this problem also resulted in the restriction of the sample to female students. Originally, I had planned to examine change in men's GRC and attitudes toward women. However, there were too few men in any one class to make statistical testing appropriate. The potential for cohort effects also precluded the option of combining data from several iterations of the class. This was a major loss in the design, and it will be important to extend the present work to populations of male students.

\section{Future directions}

The findings of the present research open the door for several additional research studies. Firstly, the simple pre-post design in Study 1 precluded an estimation of the duration of change in students' attitudes toward male role norms. Studies using follow-up measures could differentiate between different long-term attitudinal trajectories. For example, perhaps students' male role attitudes eventually return to pre-class levels. Alternatively, perhaps the class began a trend of 
increasingly progressive attitudes. This information could be used to explore possibilities of reactance or dosage (e.g., the number of class sessions attended and degree of participation in the class), and it would be particularly useful for people conceptualizing classes on masculinity as a form of intervention.

It would also be useful to identify the "active ingredients" of the class that encourage attitude change in a direction associated with improved outcomes. Past research on WGS classes has suggested that they emphasize critical thinking, openmindedness, and participatory learning (Stake \& Hoffman, 2000). However, whether these characteristics or others contribute to gender role attitude change is unknown. Are there particular processes or kinds of material that foster increasingly progressive gender role attitudes? How much and how soon should students be asked to question their existing attitudes?

Another future direction involves the exploration of a possible internal set of unified gender role attitudes. The idea that one system of gender ideology underlies both same- and other-sex role attitudes, as well as gender role conflict or stress indirectly, was alluded to in Study 3, but the results were not conclusive. Future work could compare measures of masculine ideology (equivalent to endorsement of male role norms) with feminine ideology. Since the present research was conducted, the author learned of the Femininity Ideology Scale (FIS; Levant et al., 2007a), which is the feminine counterpart to the MRNI. As discussed previously, the FIS is correlated with the MRNI-49, suggesting that there could be a common underlying dimension of 
gender ideology. The next step would be to explore influences on these attitudes: where do they come from, what changes them, and do they change interdependently?

One intriguing trend in the literature on WGS classes that remains underexplored is the relative lack of male students. All of the prior studies on WGS classes reviewed in this paper had a large majority of women in their sample (ranging from $88-94 \%$ ), a more extreme difference than would be expected even accounting for gender differences in general college enrollment and response rates. Even the course examined in the present study, which was obviously focused on men and masculinity (although cross-listed in past years between the Psychology and Women's Studies Departments), has had a disproportionately small number of men enrolled. In comparison to $28 \%$ of students taking psychology classes, based on a 2010 departmental survey, only $15 \%$ of the students receiving grades in the masculinities class were male (E. Mankowski, personal communication, December 12, 2014). More generally, between 2000 and 2014, the percentage of male students in the masculinities class has ranged from $13-32 \%(M=22, S D=.06)$. There appear to be no published data on the proportion of men in WGS classes at other institutions, save one or two anecdotal estimates. Because the material is focused on their own gender, it would seem logical that men be over-represented in the course, particularly because of the small number of classes offered at the university that are explicitly about men. As some scholars have suggested, men, as members of a dominant identity, perhaps do not believe that gender is an important topic of study (e.g., Kimmel, 1993). Or, perhaps men suspect that the course has implicitly progressive values and anticipate 
feeling uncomfortable. Pleasants' (2011) examination of men's defensive reactions to feminist classes suggests that this possibility holds some truth. However, men's engagement is critical. Firstly, society's movement toward an egalitarian structure that no longer imposes rigid gender norms requires men's participation. Secondly, the men who might feel most threatened by the material (i.e., those firmly endorsing traditional male norms and likely suffering from role conflict) would also probably stand to gain the most from the experience. Future research on gender-focused courses should explore how to increase male enrollment and improve their class experiences and outcomes.

\section{Closing thoughts}

The present research found that women in an undergraduate Psychology of Men and Masculinities course showed less endorsement of traditional male role norms at the end of the class than at the beginning. Women in the class showed decreased agreement with general prescriptive masculine role norms, the norms of aggression and self-reliance, and a composite of several other norms (including achievement/status, avoidance of femininity, homophobia, non-relational attitudes toward sex, and restrictive emotionality). Additionally, their definitions of "man" and "masculinity" included fewer references to the norms of achievement/status and aggression. There was also no evidence that students electing to enroll in the course had different pre-attitudes toward male role norms than students enrolling in a general psychology course that did not address gender. However, the small sample size and 
resulting low power of the inferential statistical analyses made it very difficult to detect differences in these two groups' male role attitudes.

This research project is the first to examine change in women's attitudes toward male role norms as well as the impact of a masculinities course on gender role attitudes. Previous research has tended to focus on attitudes toward women's roles and the impact of gender studies classes focused on women (rather than on men). Because both men's and women's attitudes toward male role norms are linked to a number of life outcomes such as health behaviors and relationship satisfaction, this research has important implications for potential interventions in the areas of healthcare or counseling. American society has a long way to go before people are free from restrictive gender role expectations, but the present research provides encouraging evidence that change is not only possible but is already happening in particular social contexts. 
Table 1

Samples used to test study hypotheses

\begin{tabular}{|c|c|c|c|c|}
\hline Study & $\begin{array}{c}\text { Sample } \\
\text { (women only) }\end{array}$ & Measure(s) $(\mathrm{N})$ & $\begin{array}{l}\text { Test statistic } \\
\text { (\# of tests } \\
\text { performed) }\end{array}$ & $\begin{array}{l}\text { Effect size } \\
\text { required for } \\
\text { significance at } \\
\text { power }=.80\end{array}$ \\
\hline \multirow[t]{2}{*}{1} & $\begin{array}{l}2011 \text { Psychology of } \\
\text { Masculinities }\end{array}$ & $\begin{array}{l}\text { MRNI } \\
(N=20)\end{array}$ & $\begin{array}{l}\text { Repeated- } \\
\text { measures } t \\
\text { test (4) }\end{array}$ & .81 \\
\hline & $\begin{array}{l}2011 \text { Psychology of } \\
\text { Masculinities }\end{array}$ & $\begin{array}{l}\text { Open-ended } \\
\text { responses to "What is } \\
\text { a man?" and "What is } \\
\text { masculinity?" } \\
(N=32)\end{array}$ & $\begin{array}{l}\text { McNemar's } \\
\text { test ( } 7)\end{array}$ & $--^{\mathrm{a}}$ \\
\hline 2 & $\begin{array}{l}2011 \text { Psychology of } \\
\text { Masculinities, } \\
2013 \text { Research } \\
\text { Methods }\end{array}$ & $\begin{array}{l}\text { MRNI } \\
\left(n_{1}=20, n_{2}=19\right)\end{array}$ & $t$ test (4) & 1.12 \\
\hline 3 & $\begin{array}{l}2012 \text { Psychology of } \\
\text { Masculinities }\end{array}$ & $\begin{array}{l}\text { MRNI and FGRS } \\
(N=32)\end{array}$ & $\begin{array}{l}\text { Pearson's } r \\
\text { (4) }\end{array}$ & .47 \\
\hline
\end{tabular}

Notes. MRNI = Male Role Norms Inventory; FGRS = Feminine Gender Role Stress Scale.

${ }^{\mathrm{a}}$ Required effect size could not be computed a priori. 
Table 2

Coding scheme for open-ended responses to the prompts "What is a man?" and "What is masculinity?"

\begin{tabular}{|c|c|c|c|c|}
\hline Code & Definition & Kappa & Scope & $\begin{array}{l}\text { Example from } \\
\text { data }\end{array}$ \\
\hline All codes & -- & .89 & -- & -- \\
\hline $\begin{array}{r}\text { Achievement/ } \\
\text { status }\end{array}$ & $\begin{array}{l}\text { Men should } \\
\text { desire and strive } \\
\text { for achievement } \\
\text { and status. }\end{array}$ & .86 & $\begin{array}{l}\text { Includes: Power, social status, } \\
\text { being a provider, being } \\
\text { respected, leadership, being } \\
\text { driven, winning }\end{array}$ & $\begin{array}{l}\text { "The less care } \\
\text { taking and more } \\
\text { hard labor or } \\
\text { CEO/Boss } \\
\text { positions are } \\
\text { more } \\
\text { masculine." }\end{array}$ \\
\hline Aggression & $\begin{array}{l}\text { Men should be } \\
\text { aggressive, } \\
\text { physically and } \\
\text { otherwise. }\end{array}$ & .97 & $\begin{array}{l}\text { Includes: physical strength and } \\
\text { toughness, risk-taking, } \\
\text { adventurousness, physical } \\
\text { protection of others, } \\
\text { fearlessness, macho }\end{array}$ & $\begin{array}{l}\text { "[Masculinity is } \\
\text { being] -tough, } \\
\text { strong, \& } \\
\text { fearless." }\end{array}$ \\
\hline $\begin{array}{r}\text { Avoidance of } \\
\text { femininity }\end{array}$ & $\begin{array}{l}\text { Men should } \\
\text { avoid being } \\
\text { feminine or } \\
\text { engaging in } \\
\text { feminine } \\
\text { activities. }\end{array}$ & .65 & $\begin{array}{l}\text { Includes: Masculinity is defined } \\
\text { in opposition to femininity } \\
\text { Excludes: Simply comparing } \\
\text { men/males to women/females } \\
\text { without defining as opposite, } \\
\text { men enjoying "manly" things } \\
\text { like sports (unless the activities } \\
\text { are compared to feminine } \\
\text { activities), biological difference } \\
\text { from females (see Gender as } \\
\text { biologically determined) }\end{array}$ & $\begin{array}{l}\text { "The level of } \\
\text { masculinity is } \\
\text { described by } \\
\text { how well a man } \\
\text { fits into the } \\
\text { antifeminine } \\
\text { role." }\end{array}$ \\
\hline $\begin{array}{r}\text { Fear and hatred } \\
\text { of homosexuals } \\
\text { / Homophobia }\end{array}$ & $\begin{array}{l}\text { Men should } \\
\text { avoid acting in } \\
\text { a way that } \\
\text { could imply } \\
\text { homosexuality. }\end{array}$ & $1^{\mathrm{a}}$ & $\begin{array}{l}\text { Includes: Restrictive behavior } \\
\text { specifically toward other men, } \\
\text { avoiding gay men, men are only } \\
\text { heterosexual } \\
\text { Excludes: Just engaging in } \\
\text { heterosexual activity (isn't } \\
\text { necessarily anti-gay) }\end{array}$ & $\begin{array}{l}\text { "[Masculinity is] } \\
\text {...not having } \\
\text { feminine } \\
\text { characteristics } \\
\text { (homosexual).... } \\
\text { " }\end{array}$ \\
\hline $\begin{array}{r}\text { Non-relational } \\
\text { attitudes toward } \\
\text { sex }\end{array}$ & $\begin{array}{l}\text { Men should be } \\
\text { highly sexual } \\
\text { and focused on } \\
\text { their physical } \\
\text { pleasure. }\end{array}$ & 1 & $\begin{array}{l}\text { Includes: Strong sex drive, focus } \\
\text { on own sexual pleasure, being } \\
\text { "good in bed," being sexually } \\
\text { dominant } \\
\text { Excludes: Loving one's sex } \\
\text { partner }\end{array}$ & $\begin{array}{l}\text { "[A man is }] \text {... } \\
\text { non-virgin, being } \\
\text { at least mid- } \\
\text { twenties...." }\end{array}$ \\
\hline $\begin{array}{r}\text { Restrictive } \\
\text { emotionality }\end{array}$ & $\begin{array}{l}\text { Men should not } \\
\text { outwardly } \\
\text { express their } \\
\text { emotions. }\end{array}$ & .84 & $\begin{array}{l}\text { Includes: Emotional } \\
\text { detachment/toughness, } \\
\text { emotional stability } \\
\text { Excludes: restrictive } \\
\text { emotionality specifically with } \\
\text { men (see Homophobia), } \\
\text { fearlessness (see Aggression) }\end{array}$ & $\begin{array}{l}\text { "Men are not as } \\
\text { emotional as } \\
\text { women. Men } \\
\text { don't cry." }\end{array}$ \\
\hline Self-reliance & $\begin{array}{l}\text { Men should be } \\
\text { able to rely }\end{array}$ & .68 & $\begin{array}{l}\text { Includes: problem-solving, being } \\
\text { logical/level-headed/realistic, }\end{array}$ & $\begin{array}{l}\text { "A man ... has } \\
\text { learned to }\end{array}$ \\
\hline
\end{tabular}




\begin{tabular}{lll}
\hline $\begin{array}{l}\text { upon } \\
\text { themselves and } \\
\text { make decisions }\end{array}$ & responsibility, reliability, & function in \\
independence & society as an \\
by themselves. & Excludes: Control over others & individual adult. \\
\hline
\end{tabular}

${ }^{\mathrm{a}}$ This theme was not present in the data set. 
Table 3

Internal consistency (Cronbach's alpha) of the MRNI and FGRS

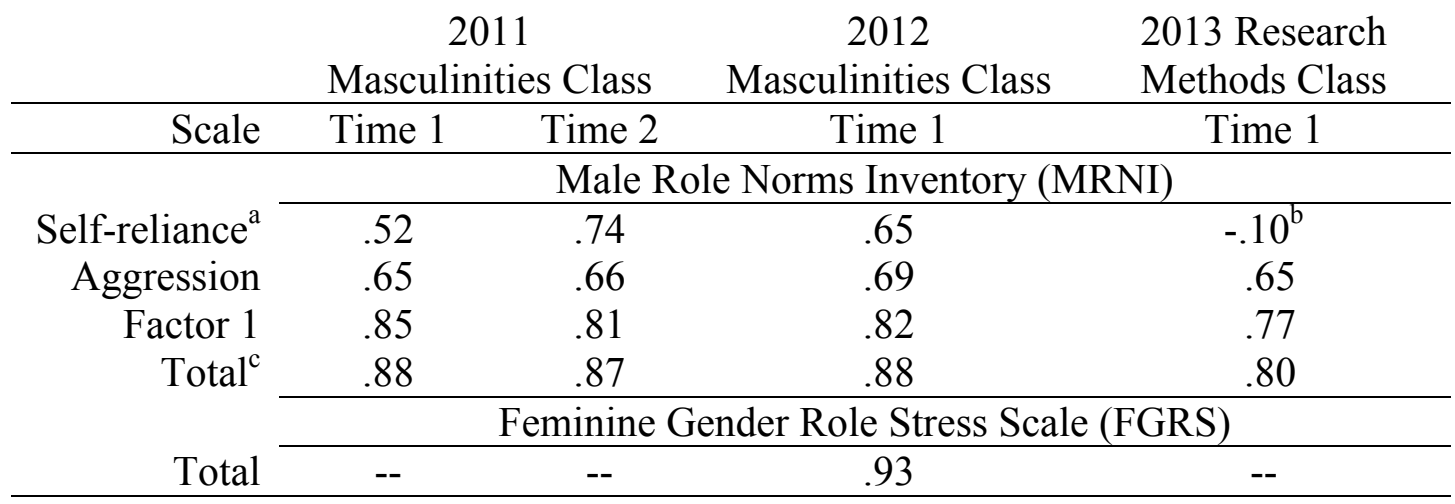

Note. Item \#21 of the MRNI ("A man who take a long time and has difficulty making decisions will usually not be respected") was removed due to its negative impact on the internal consistency of the scale.

${ }^{a}$ Including item $\# 21$, row statistics are: .44, .68, .53, .07.

${ }^{b}$ While removal of MRNI item \#10 ("A man must be able to make his own way in the world") would increase this reliability to .40 (the maximum possible with removal of only one item), this action would also severely decrease the reliabilities of this subscale in the other samples. Thus, improvement in this sample was not attempted. ${ }^{\circ}$ Including item $\# 21$, row statistics are: $.88, .88, .87, .79$. 


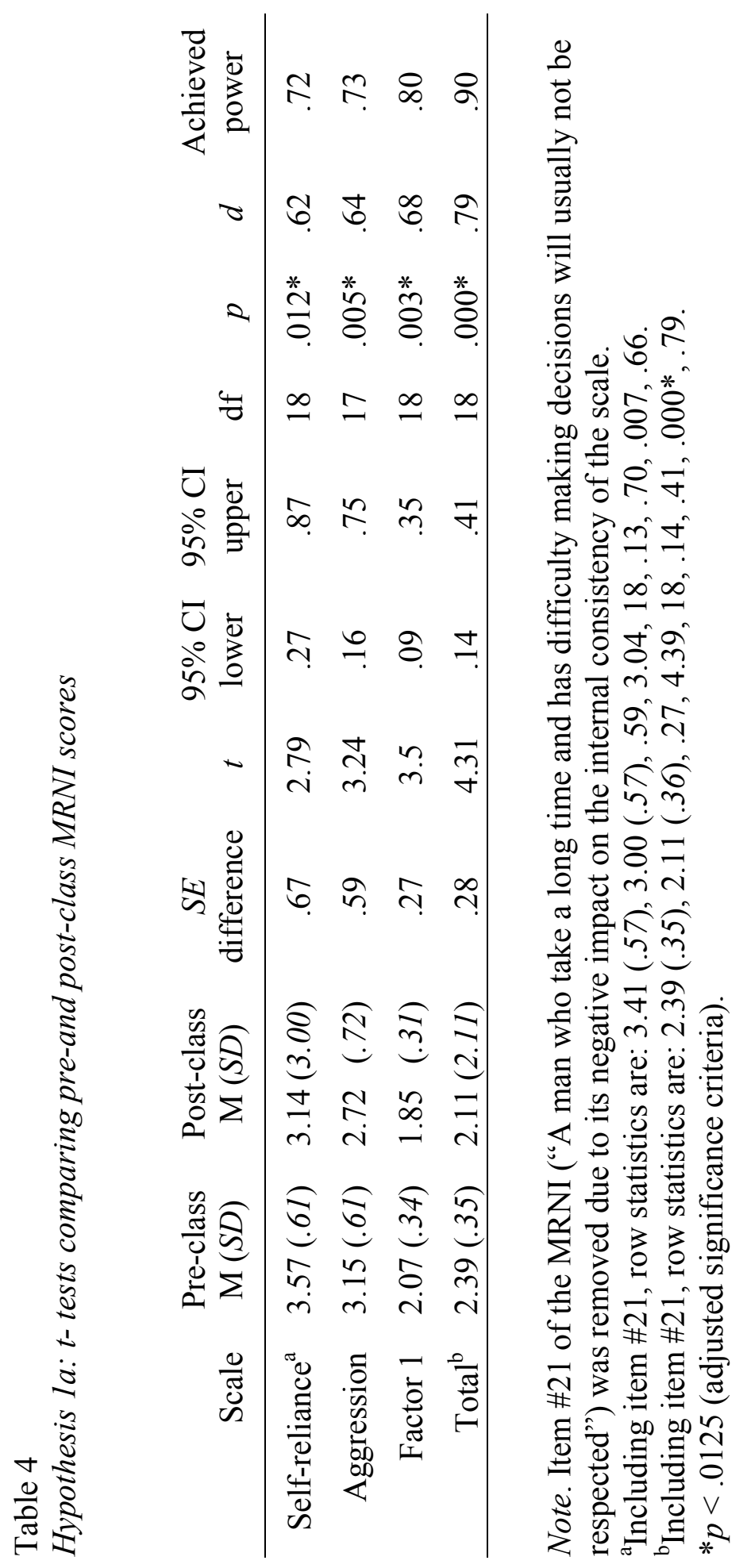




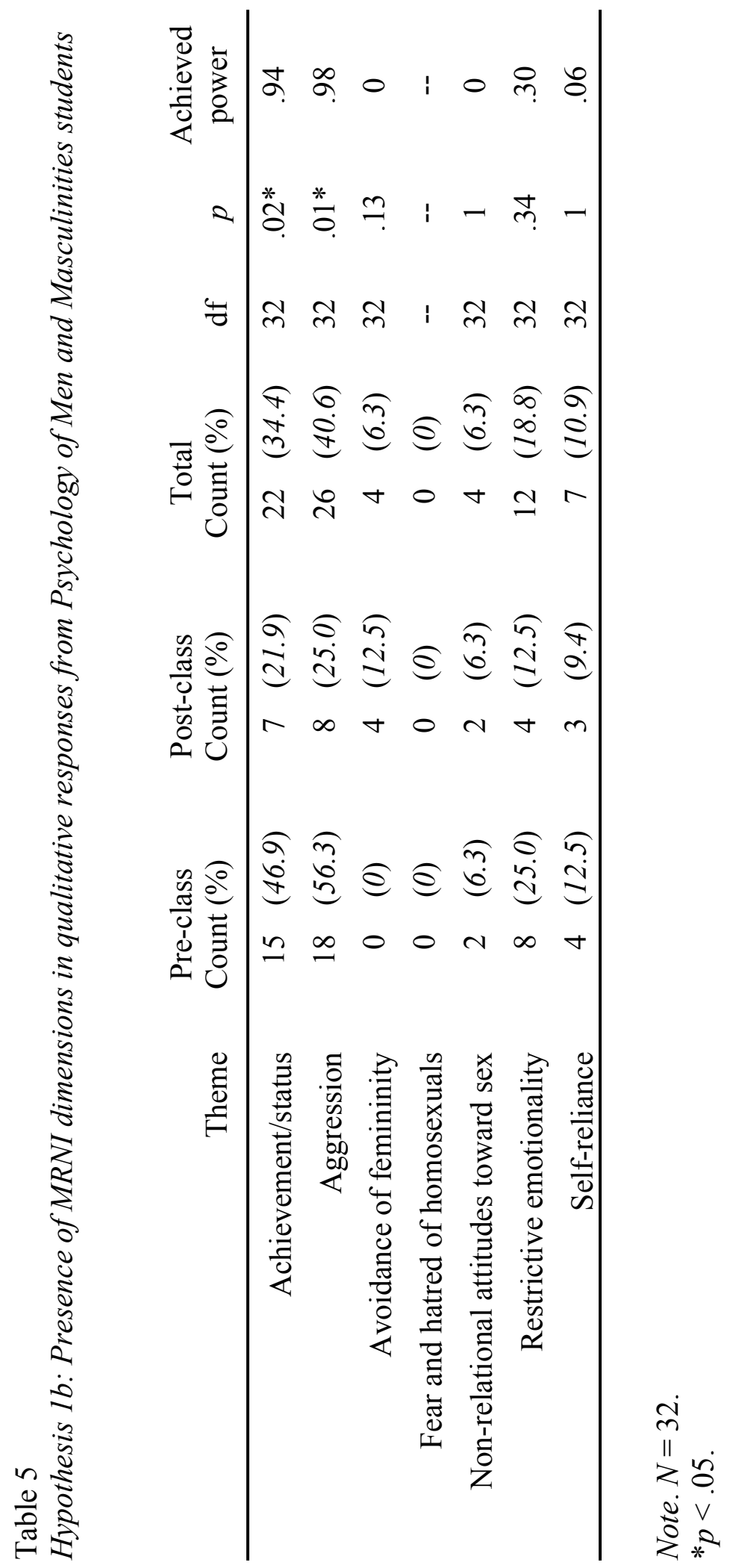




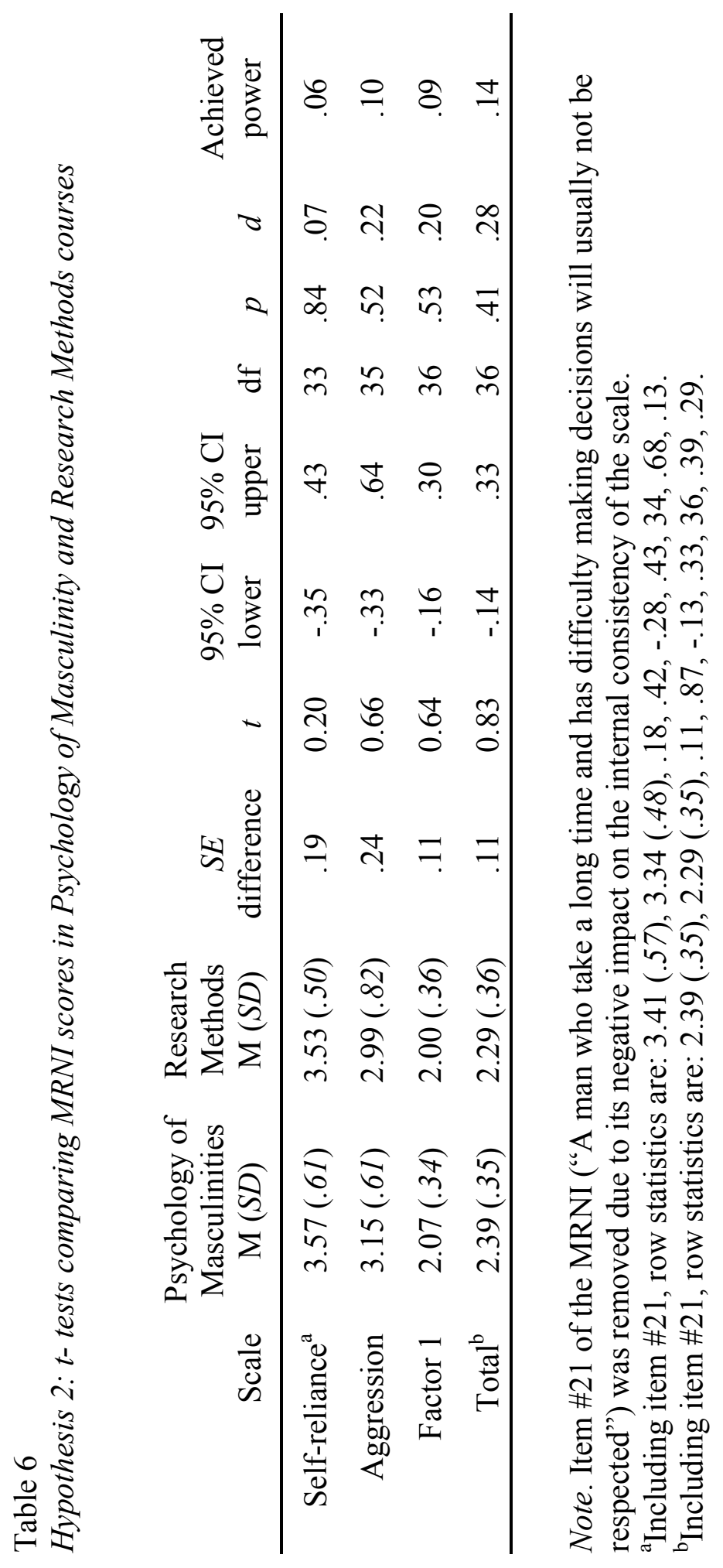


Table 7

Hypothesis 3: Correlation of FGRS (total) and MRNI (total and subscales)

\begin{tabular}{rrrccccc} 
& Scale & $\mathrm{M}(S D)$ & 1 & 2 & 3 & 4 & $\begin{array}{c}\text { Achieved power } \\
\text { (column 1) }\end{array}$ \\
\hline 1 & FGRS total & $4.45(.73)$ & -- & & & & -- \\
2 & MRNI total & $2.43(.41)$ & .20 & -- & & & .20 \\
3 & Self-reliance & $3.49(.75)$ & -.08 & $.67^{* *}$ & -- & & .07 \\
4 & Aggression & $3.18(.78)$ & .30 & $.78^{* *}$ & $.45^{*}$ & -- & .39 \\
5 & Factor 1 & $2.14(.37)$ & .20 & $.96^{* *}$ & $.52^{*}$ & $.62^{* *}$ & .20 \\
\hline
\end{tabular}

Note. FGRS = Feminine Gender Role Stress; MRNI = Male Role Norms Inventory; $N$ $=32$.

$* p<.05$.

$* * p<.001$. 


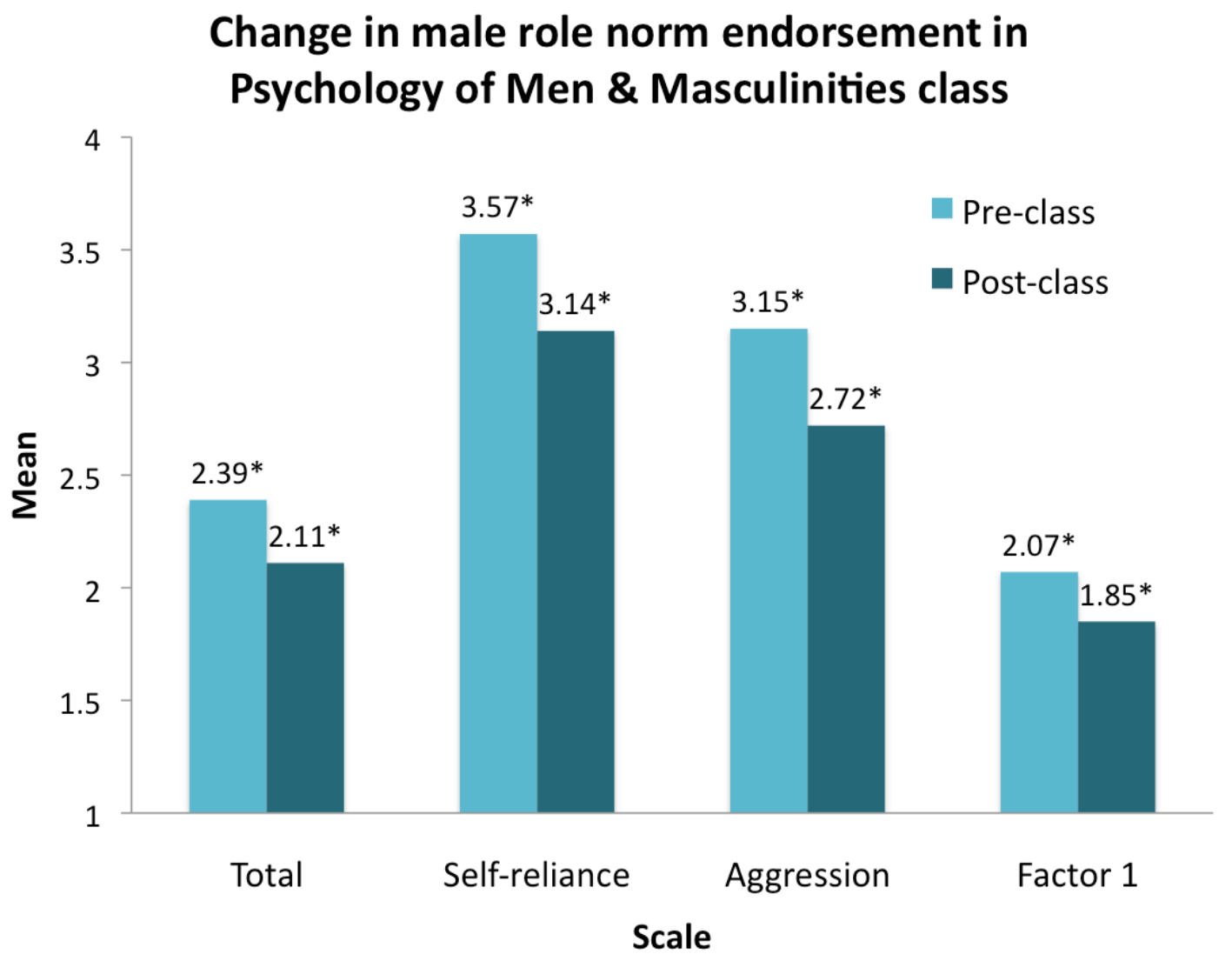

Figure 1. Change in male role norm endorsement in the Psychology of Men and Masculinities class. 


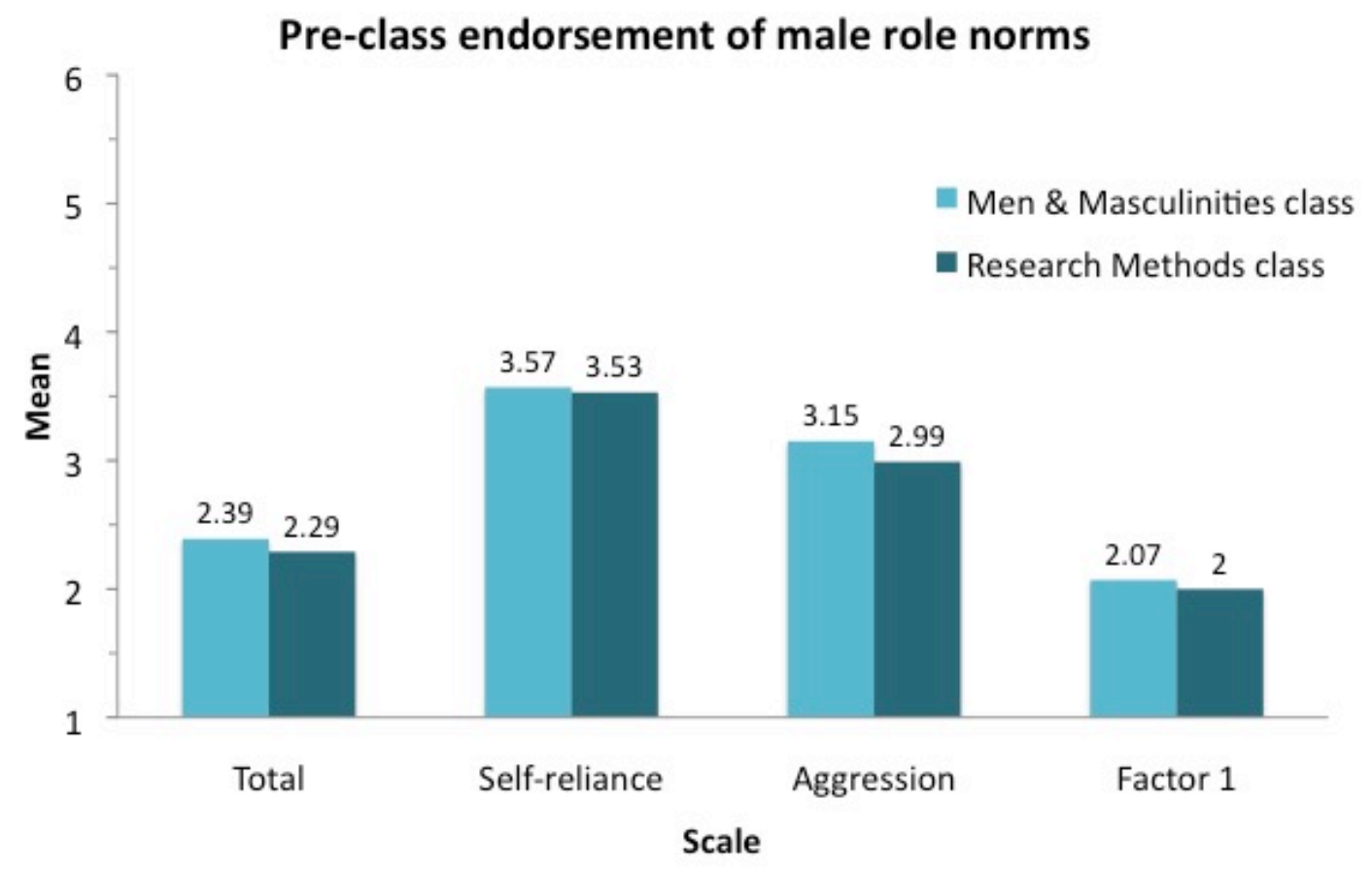

Figure 2. Pre-class mean endorsement of male role norms in the Men and Masculinities class compared to the Research Methods class. 


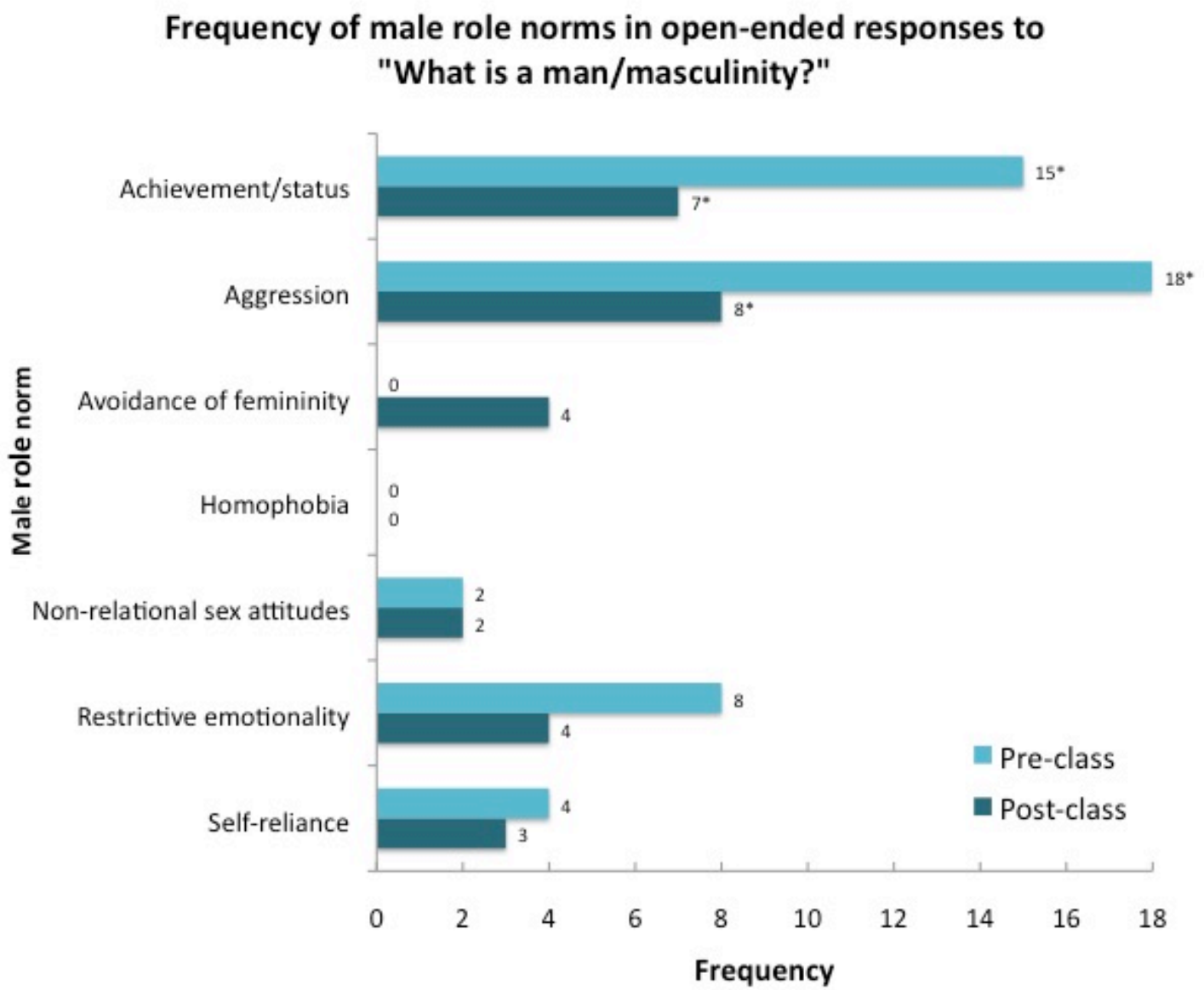

Figure 3. Frequency of male role norms referenced in responses to "What is a man/ masculinity?" at the beginning and the end of the class. 


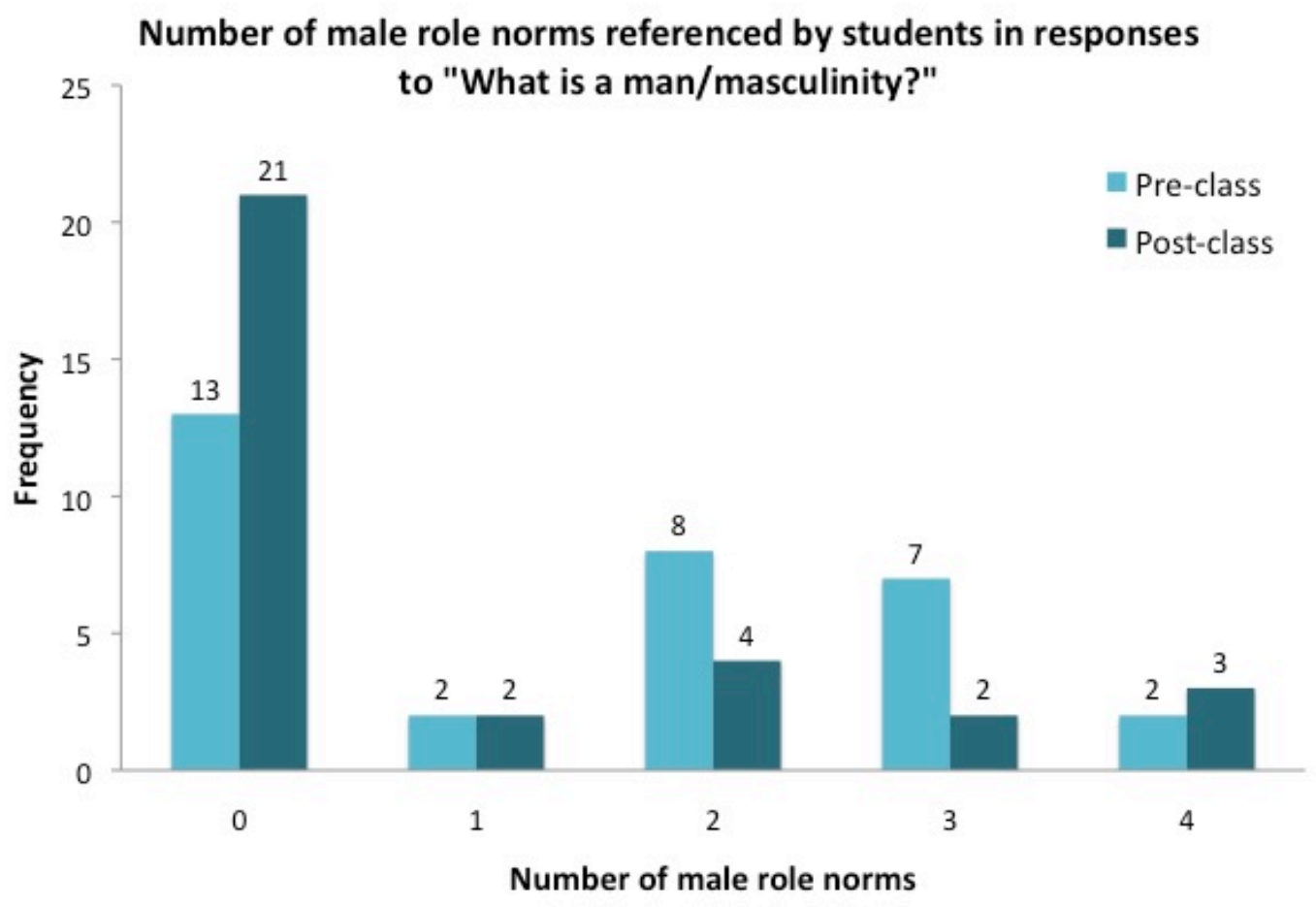

Figure 4. Number of male role norms referenced responses to "What is a man/masculinity?" 


\section{References}

Backus, F. R., \& Mahalik, J. R. (2011). The masculinity of Mr. Right: Feminist identity and heterosexual women's ideal romantic partners. Psychology of Women Quarterly, 35, 318-326. doi:10.1177/0381684310392347

Banaji, M. R., \& Heiphetz, L. (2010). Attitudes. In S. T. Fiske, D. T. Gilbert, \& G. Lindzey (Eds.), Handbook of social psychology (pp. 353-393). New York, NY: Wiley.

Barrett, A. E., \& White, H. R. (2002). Trajectories of gender role orientations in adolescence and early adulthood: A prospective study of the mental health effects of masculinity and femininity. Journal of Health and Social Behavior, $43,451-468$.

Becker, J. C., \& Swim, J. K. (2012). Reducing endorsement of benevolent and modern sexist beliefs: Differential effects of addressing harm versus pervasiveness of benevolent sexism. Social Psychology, 43, 127-137. doi:10.1027.1864$9335 / \mathrm{a} 000091$

Bekker, M. H. J., \& Boselie, K. A. H. M. (2002). Gender and stress: Is gender role stress? A re-examination of the relationship between feminine gender role stress and eating disorders. Stress \& Health, 18, 141-149. doi:10.1002/smi.933

Bem, S. L. (1974). The measurement of psychological androgyny. Journal of Consulting and Clinical Psychology, 42, 155-162.

Berger, J. M., Levant, R., McMillan, K. K., Kelleher, W., \& Sellers, A. (2005). Impact of gender role conflict, traditional masculinity ideology, alexithymia, and age 
on men's attitudes toward psychological help seeking. Psychology of Men \& Masculinity, 6, 73-78.

Binder, D. M., \& Bourgeois, M. J. (2006). Direct and indirect effects of group discussion on consensus. Social Influence, 1, 249-264.

Black, B. M. (1994). Students' attitudes toward women: Do social work programs make a difference? Affilia, 9, 417-436. doi:10.1177/088610999400900406

Blazina, C., \& Watkins, C. E. (1996). Masculine gender role conflict: Effects on college men's psychological well-being, chemical substance usage, and attitudes toward help-seeking. Journal of Counseling Psychology, 43, 461-465.

Blazina, C., \& Watkins, C. E. (2000). Separation/individuation, parental attachment, and male gender role conflict: Attitudes toward the feminine and the fragile masculine self. Psychology of Men \& Masculinity, 1, 126-132. doi:10.1037//1524-9220.1.2.126

Blee, K. M., \& Tickamyer, A. R. (1995). Racial differences in men's attitudes about women's gender roles. Journal of Marriage and the Family, 57, 21-30.

Bonney, J. F., Kelley, M. L., \& Levant, R. F. (1999). A model of fathers' behavioral involvement in child care. Journal of Family Psychology, 13, 401-415.

Brannon, L. (2011). Gender: Psychological perspectives (6th ed.). S. Hartman \& K. Kikel (Eds.). Boston, IL: Allyn \& Bacon.

Brooks, C., \& Bolzendahl, C. (2004). The transformation of US gender role attitudes: Cohort placement, social-structural change, and ideological learning. Social Science Research, 33, 106-133. doi:10.1016/S0049-089X(03)00041-3 
Bryant, A. N. (2003). Changes in attitudes toward women's roles: Predicting genderrole traditionalism among college students. Sex Roles, 48, 131-142.

Burn, S. M., \& Ward, A. Z. (2005). Men's conformity to traditional masculinity and relationship satisfaction. Psychology of Men \& Masculinity, 6, 254-263. doi:10.1037/1524-9220.6.4.254

Campbell, J. L., \& Snow, B. M. (1992). Gender role conflict and family environment as predictors of men's marital satisfaction. Journal of Family Psychology, 6, 84-87.

Cohn, A., \& Zeichner, A. (2006). Effects of masculine identity and gender role stress on aggression in men. Psychology of Men \& Masculinity, 7, 179-190. doi:10.1037/1524-9220.7.4.179

Cortina, J. M. (1993). What is coefficient alpha? An examination of theory and application. Journal of Applied Psychology, 78, 98-104.

Cournoyer, R. J., \& Mahalik, J. R. (1995). Cross-sectional study of gender role conflict examining college-aged and middle-aged men. Journal of Counseling Psychology, 42, 11-19.

Courtenay, W. H. (2000). Engendering health: A social constructivist examination of men's health beliefs and behaviors. Psychology of Men \& Masculinity, 1, 4-15.

Davidson, M. (2007). Seeking refuge under the umbrella: Inclusion, exclusion, and organizing within the category transgender. Sexuality Research \& Social Policy, 4, 60-80. 
Deaux, K., \& Major, B. (1987). Putting gender into context: An interactive model of gender-related behavior. Psychological Review, 94, 369-389.

DiDonato, M. D., \& Berenbaum, S. A. (2011). The benefits and drawbacks of gender typing: How different dimensions are related to psychological adjustment. Archives of Sexual Behavior, 40, 457-463. doi:10.1007/s10508-010-9620-5

Factor, R., \& Rothblum, E. (2008). Exploring gender identity and community among three groups of transgender individuals in the United States: MTFs, FTMs, and genderqueers. Health Sociology Review, 17, 235-253.

Fan, P., \& Marini, M. M. (2000). Influences on gender-role attitudes during the transition to adulthood. Social Science Research, 29, 258-283.

doi:10.1006/ssre.1999.0669

Faul, F., Erdfelder, E., Lang, A. G., \& Buchner, A. (2007). G*Power 3: A flexible statistical power analysis program for the social, behavioral, and biomedical sciences. Behavior Research Methods, 39, 175-191.

Freud, S. (1905). Three essays on the theory of sexuality. New York, NY: Basic Books.

Gale, S. R. (1999). A phenomenological analysis of masculinity ideologies among college males. Dissertation Abstracts International, 60(10), 5250.

Gillespie, B. L., \& Eisler, R. M. (1992). Development of the Feminine Gender Role Stress Scale: A cognitive-behavioral measure of stress, appraisal, and coping for women. Behavior Modification, 16, 426-438.

doi:10.1177/01454455920163008 
Glick, P., \& Fiske, S. T. (1996). The Ambivalent Sexism Inventory: Differentiating hostile and benevolent sexism. Journal of Personality and Social Psychology, 70, 491-512.

Glick, P., Fiske, S. T., Masser, B., Manganelli, A. M., Huang, L., Castro, Y. R., Willemsen, T. M., Six-Materna, I., Lameiras, M., Eckes, T., Volpato, C., Pek, J. C. X., Sakalli-Ugurlu, N., Pereira, M. L. D., Brunner, A., \& Wells, R. (2004). Bad but bold: Ambivalent attitudes toward men predict gender inequality in 16 nations. Journal of Personality and Social Psychology, 86, 713-728. doi:10.1037/002-3514.86.5.713

Glomb, S. M., \& Espelage, D. L. (2005). The influence of restrictive emotionality in men's emotional appraisal of sexual harassment: A gender role interpretation. Psychology of Men \& Masculinity, 6, 240-253. doi:10.1037/1524-9220.6.4.240

Good, G., E., Robertson, J. M., O’Neil, J. M., Fitzgerald, L. F., Stevens, M., DeBord, K. A., Bartels, K. M., \& Braverman, D. G. (1995). Journal of Counseling Psychology, 42, 3-10.

Good, J. J., \& Sanchez, D. T. (2010). Doing gender for different reasons: Why gender conformity positively and negatively predicts self-esteem. Psychology of Women Quarterly, 34, 203-214.

Hayes, J. A., \& Mahalik, J. R. (2000). Gender role conflict and psychological distress in male counseling center clients. Psychology of Men \& Masculinity, 1, 116125. 
Hegleson, V. S. (1994). Prototypes and dimensions of masculinity and femininity. Sex Roles, 31, 653-682.

Henrich, J., Heine, S. J., \& Norenzayan, A. (2010). The weirdest people in the world? Behavioral and Brain Sciences, 33, 61-135.

Herdman, K. J., Choi, N., Fuqua, D. R., \& Newman, J. L. (2012). Gender Role Conflict Scale: Validation for a sample of gay men and lesbian women. Psychological Reports, 110, 227-232. doi:10.2466/02.07.PR0.110.1.227-232

Houle, J., Mishara, B. L., \& Chagnon, F. (2008). An empirical test of a mediation model of the impact of the traditional male gender role on suicidal behavior in men. Journal of Affective Disorders, 107, 37-43. doi:10.1016/j.jad.2007.07.016

Jome, L. M., \& Tokar, D. M. (1998). Dimensions of masculinity and major choice traditionality. Journal of Vocational Behavior, 52, 120-134.

Kassing, L. R., Beesley, D., Frey, L. L. (2005). Gender role conflict, homophobia, age, and education as predictors of male rape myth acceptance. Journal of Mental Health Counseling, 27, 311-328.

Kazmierczak, M. (2010). The feminine and masculine gender role stress: Conclusions from Polish studies. Polish Psychological Bulletin, 41, 20-30. doi:10.2478/s10059-010-0003-5

Kilianski, S. E. (2003). Explaining heterosexual men's attitudes toward women and gay men: The theory of exclusively masculine identity. Psychology of Men \& Masculinity, 4, 37-56. doi:10.1037/1524-9220.4.1.37

Kilmartin, C. (2009). The masculine self. Cornwall-on-Hudson, NY: Sloan Publishing. 
Kimmel, M. S. (1993). Invisible masculinity. Society, 30, 28-35.

Kimmel, M. S., \& Messner, M. A. (2012). Men's lives. Boston, MA: Pearson.

King, L. A., \& King, D. W. (1997). Sex-Role Egalitarianism Scale: Development, psychometric properties, and recommendations for future research. Psychology of Women Quarterly, 21, 71-97. doi:10.1111/j.1471-6402.1997.tb00101.x

Landis, J. R., \& Koch, G. G. (1977). The measurement of observer agreement for categorical data. Biometrics, 33, 159-174.

Levant, R. F., Hirsch, L., Celentano, E., Cozza, T., Hill, S., MacEachern, M., Marty, N., \& Schnedeker, J. (1992). The male role: An investigation of norms and stereotypes. Journal of Mental Health Counseling, 14, 325-337.

Levant, R. F., Majors, R. G., \& Kelley, M. L. (1998). Masculine ideology among young African American and European American women and men in different regions of the United States. Cultural Diversity and Mental Health, 4, $227-$ 236.

Levant, R. F., \& Richmond, K. (2007). A review of research on masculinity ideology using the Male Role Norms Inventory. The Journal of Men's Studies, 15, 130146.

Levant, R. F., Richmond, K., Cook, S., House, A. T., \& Aupont, M. (2007a). The Femininity Ideology Scale: Factor structure, reliability, convergent and discriminant validity, and social contextual variation. Sex Roles, 57, 373-383.

Levant, R. F., Smalley, K. B., Aupont, M., House, A. T., Richmond, K., \& Noronha, D. (2007b). Initial validation of the Male Role Norms Inventory-Revised 
(MRNI-R). The Journal of Men's Studies, 15, 83-100.

doi:10.3149/jms.1501.83

Lopez, F. G., Fons-Scheyd, A., Bush-King, I., \& McDermott, R. C. (2011). A latent class analysis of dyadic perfectionism in a college sample. Measurement and Evaluation in Counseling and Development, 44, 32-51. doi: $10.1177 / 0748175610391610$

Mahalik, J. R., Addis, M. E., Kilmartin, C., \& O’Neil, J. M. (2013). Complexities and challenges when teaching the psychology of men: Experienced professors discuss their pedagogical processes. Psychology of Men \& Masculinity, 14, $248-255$.

Mahalik, J. R., Locke, B. D., Ludlow, L. H., Diemer, M. A., Scott, R. P. J., Gottfried, M., \& Freitas, G. (2003). Development of the Conformity to Masculine Norms Inventory. Psychology of Men \& Masculinity, 4, 3-25. doi:10.1037/15249220.4.1.3

Mahalik, J. R., Locke, B. D., Theodore, H., Cournoyer, R. J., \& Lloyd, B. F. (2001). A cross-national and cross-sectional comparison of men's gender role conflict and its relationship to social intimacy and self-esteem. Sex Roles, 45, 1-14. Malkin, C., \& Stake, J. E. (2004). Changes in attitudes and self-confidence in the women's studies classroom: The role of teacher alliance and student cohesion. Sex Roles, 50, 455-468. 
Martz, D. M., Handley, K. B., \& Eisler, R. M. (1995). The relationship between feminine gender role stress, body image, and eating disorders. Psychology of Women Quarterly, 19, 493-508.

McCreary, D. R., Saucier, D. M., \& Courtenay, W. H. (2005). The drive for muscularity and masculinity: Testing the associations among gender-role traits, behaviors, attitudes, and conflict. Psychology of Men \& Masculinity, 6, 83-94. doi:10.1037/1524-9220.6.2.83

Mcgraw, S. L. (2001). Masculinity ideologies, men’s relationship behavior, and relationship satisfaction in heterosexual couple relationships. Dissertation Abstracts International, 62(3), 1588B.

Morgan, D. L. (2007). Paradigms lost and pragmatism regained: Methodological implications combining qualitative and quantitative methods. Journal of Mixed Methods, 1, 48-76.

Moore, T. M., \& Stuart, G. L. (2005). A review of the literature on masculinity and partner violence. Psychology of Men \& Masculinity, 6, 46-61.

Mussap, A. J. (2007). Short communication: The relationship between feminine gender role stress and disordered eating symptomatology in women. Stress and Health, 23, 343-348. doi:10.1002/smi. 1152

Nichols, D. P. (1999). My coefficient a is negative! SPSS Keywords. Retrieved from http://www.ats.ucla.edu/stat/spss/library/negalpha.htm

O’Neil, J. M. (1986). Gender-role Conflict Scale: College men’s fear of femininity. Sex Roles, 14, 335-350. 
O’Neil, J. M. (2008). Summarizing 25 years of research on men's gender role conflict using the Gender Role Conflict Scale: New research paradigms and clinical implications. The Counseling Psychologist, 26, 358-445.

doi: $10.1177 / 0011000008317057$

O’Neil, J. M., Helms, B., Gable, R., David, L., \& Wrightsman, L. (1986). Gender Role Conflict Scale: College men's fear of femininity. Sex Roles, 14, 335-350.

O’Neil, J. M., \& Renzulli, S. (2013a). Introduction to the special section: Teaching the psychology of men - a call to action. Psychology of Men \& Masculinity, 14, 221-229. doi:10.1037/a0033258

O’Neil, J. M., \& Renzulli, S. (2013b). Teaching the psychology of men: A national survey of professors' attitudes and content analyses of their courses. Psychology of Men \& Masculinity, 14, 230-239. doi:10.1037/a0033255

Perry, K. L. (2010). Gender role and women's health: Effects offeminine gender role stress and femininity on somatic symptoms and sexual functioning. Unpublished doctoral dissertation. Seattle Pacific University, Seattle: WA.

Pleasants, R. K. (2011). Men learning feminism: Protecting privileges through discourses of resistance. Men and Masculinities, 14, 230-250. doi:10.1177/1097184X11407048

Pleck, J. (1981). The myth of masculinities. Cambridge, MA: The Massachusetts Institute of Technology Print. 
Portland State University Office of Institutional Research and Planning (PSU OIRP). (2013). Student statistical portrait 2012-2013. Retrieved from http://www.oirp.pdx.edu/source/

port1213/all_all.pdf

Rando, R. A., Rogers, J. R., \& Brittan-Powell, C. S. (1998). Gender role conflict and college men's sexually aggressive attitudes and behavior. Journal of Mental Health Counseling, 20, 359-370.

Rice, S., Fallon, B., \& Bambling, M. (2011). Men and depression: Masculine role norms throughout the lifespan. The Australian Educational and Developmental Psychologist 28, 133-144. doi:10.1375/aedp.28.2.133

Robinson, D. T., \& Schwartz, J. P. (2004). Relationship between gender role conflict and attitudes toward women and African Americans. Psychology of Men \& Masculinity, 5, 65-71. doi:10.1037/1524-9220.5.1.65

Royce, S., \& Christiansen, J. B. (1977). The construct validation of a short-form attitudes toward feminism scale. Sociology \& Social Research, 61, 294-303.

Rudman, L. A. (1998). Self-promotion as a risk factor for women: The costs and benefits of counterstereotypical impression management. Journal of Personality and Social Psychology, 74, 629-645.

Rudman, L. A., \& Fairchild, K. (2004). Reactions to counterstereotypic behavior: The role of backlash in cultural stereotype maintenance. Journal of Personality and Social Psychology, 87, 157-176. doi:10.1037/0022-3514.87.2.157 
Sanchez-Lopez, M. P., Cuellar-Flores, I., \& Dresch, V. (2012). The impact of gender roles on health. Women \& Health, 52, 182-196.

doi:10.1080/03630242.2011.652352

Schwartz, J. P., Waldo, M., \& Daniel, D. (2005). Gender-role conflict and self-esteem: Factors associated with partner abuse in court-referred men. Psychology of Men \& Masculinity, 6, 109-114. doi:7/1524-9220.6.2.109

Sevelius, J. M., \& Stake, J. E. (2003). The effects of prior attitudes and attitude importance on attitude change and class impact in women's and gender studies. Journal of Applied Social Psychology, 33, 2341-2353.

Shepard, D. S. (2002). A negative state of mind: Patterns of depressive symptoms among men with high gender role conflict. Psychology of Men and Masculinity, 3, 3-8. doi:10.1037//1524-9220.3.1.3

Siebler, K. (2012). Transgender transitions: Sex/gender binaries in the digital age. Journal of Gay and Lesbian Mental Health, 16, 74-99. doi:10.1080/19359705.2012.632751

Smith, J. A. I. (1996). Assessment of gender variables in heterosexual condom use. Unpublished master's thesis, University of North Dakota.

Spence, J. T., \& Helmreich, R. L. (1972). The Attitudes Toward Women Scale: An objective instrument to measure attitudes toward the rights and roles of women in contemporary society. JSAS Catalog of Selected Documents in Society, 2, 667-668. 
Stake, J. E., \& Hoffmann, F. L. (2000). Putting feminist pedagogy to the test: The experience of women's studies from student and teacher perspectives. Psychology of Women Quarterly, 24, 30-38.

Stake, J. E., \& Hoffmann, F. L. (2001). Changes in student social attitudes, activism, and personal confidence in higher education: The role of women's studies. American Educational Research Journal, 38, 411-436.

Stake, J. E., Roades, L., Rose, S., Ellis, L., \& West, C. (1994). The women's studies experience: Impetus for feminist activism. Psychology of Women Quarterly, $18,17-24$

Stake, J. E., \& Rose, S. (1994). The long-term impact of women's studies on students' personal lives and political activism. Psychology of Women Quarterly, 18, 403412.

Stulhofer, A., Busko, V., \& Brouillard, P. (2010). Development and bicultural validation of the New Sexual Satisfaction Scale. Journal of Sex Research, 47, 257-268. doi:10.1080/00224490903100561

Tallichet, S. E., \& Willits, F. K. (1986). Gender-role attitude change of young women: Influential factors from a panel study. Social Psychology Quarterly, 49, 219-227.

Theodore, H., \& Lloyd, B. F. (2000). Age and gender role conflict: A cross-sectional study of Australian men. Sex Roles, 42, 1027-1042.

Thompson, E. H., \& Pleck, J. H. (1986). The structure of male role norms. American Behavioral Scientist, 29, 531-543. 
Thornton, A., Alwin, D. F., \& Camburn, D. (1983). Causes and consequences of sexrole attitudes and attitude change. American Sociological Review, 48, 211-227.

United States Census Bureau. (2014). State \& county quickfacts: Oregon. Retrieved from http://quickfacts.census.gov/qfd/states/41000.html

Vandello, J. A., \& Bosson, J. K. (2013). Hard won and easily lost: A review and synthesis of theory and research on precarious manhood. Psychology of Men \& Masculinity, 14, 101-113. doi:10.1037/a0029826

Vescio, T. K., Sechrist, G. B., \& Paolucci, M. P. (2003). Perspective taking and prejudice reduction: the mediational role of empathy arousal and situational attributions. European Journal of Social Psychology, 33, 455-472. doi:10.1002/ejsp.163

Vogel, D. L., Tucker, C. M., Wester, S. R., \& Heesacker, M. (1999). The impact of sex and situational cues on the endorsement of traditional gender-role attitudes and behaviors in dating couples. Journal of Social and Personal Relationships, 16, 459-473. doi:10.1177/0265407599164003

Wade, J. C., \& Brittan-Powell, C. (2001). Men's attitudes toward race and gender equity: The importance of masculinity ideology, gender-related traits, and reference group identity dependence. Psychology of Men \& Masculinity, 2, 4250. doi:10.1037//1524-9220.2.1.42

Walker, D. F., Tokar, D. M., \& Fischer, A. R. (2000). What are eight popular masculinity-related instruments measuring? Underlying dimensions and their 
relations to sociosexuality. Psychology of Men \& Masculinity, 1, 98-108. doi:10.1037//1524-9220.1.2.98

Wester, S. R. (2008). Multicultural advances in the psychology of men: Implications for counseling psychology. The Counseling Psychologist, 36, 294-324. doi: $10.1177 /$

0011000006286341

Wilkinson, W. W. (2004). Authoritarian hegemony, dimensions of masculinity, and male antigay attitudes. Psychology of Men \& Masculinity, 5, 121-131. doi:10.1037/1524-9220.5.2.121

Witt, M. G., \& Wood, W. (2010). Self-regulation of gendered behavior in everyday life. Sex Roles, 62, 635-646. doi:10.1007/s11199-010-9761-y

Woller, K. M. P., Buboltz, W. C., \& Loveland, J. M. (2007). Psychological reactance: Examination across age, ethnicity, and gender. The American Journal of Psychology, 120, 15-24.

Wood, W. (2000). Attitude change: Persuasion and social influence. Annual Review of Psychology, 51, 539-570.

Wood, W., Christensen, N., Hebl, M. R., \& Rothgerber, H. (1997). Conformity to sextyped norms, affect, and the self-concept. Journal of Personality and Social Psychology, 73, 523-535.

Wood, W., \& Eagly, A. H. (2012). Biosocial construction of sex differences and similarities in behavior. Advances in Experimental Social Psychology, 46, 55123. doi:10.1016/B978-0-12-394281-4.00002-7 


\section{Appendix A \\ Consent Form \\ PORTLAND STATE UNIVERSITY \\ Department of Psychology}

\section{Consent Form}

\section{"Psychology of Men and Masculinity" Course Evaluation Follow-up}

You are being asked to complete an online survey regarding your beliefs about men and/or women and your sexual experiences. This study is being conducted by Professor Eric Mankowski and his graduate student, Sylvia Kidder. Please answer as honestly as possible; participation is confidential, and the researchers have no way of knowing whether you choose to participate or what your responses are.

You may experience some discomfort answering personal questions about your beliefs or sexual experiences. However, the risk associated with your participation in this study is minimal, and you are free to skip questions or withdraw from the survey at any time. Choosing to forego or stop the study will not adversely affect your class grade or your relationship with the researchers, the Psychology Department, or Portland State University.

This survey should take about 15-25 minutes to complete. By participating in this study you will be helping PSU understand the value and practical effects of taking Psychology of Men and Masculinity; it may also help your instructor improve the course for future students. Additionally, you will be making a valuable contribution to the study of sexuality.

If you have any questions or concerns, please contact Professor Mankowski (mankowskie@pdx.edu) or Sylvia Kidder (sylvia2@pdx.edu). We would be happy to provide you with the study's results after the quarter ends. Your time and participation are greatly appreciated!

By clicking "I agree" below, you are consenting to participate in this study.

○ I agree

- I do not agree 


\section{Appendix B}

Survey Flow and Content

- Consent Form (Appendix A)

- Please enter the name of your favorite pet. If you don't have a pet, please enter your mother's maiden name. (This unique name is used to match survey responses from the beginning and end of the quarter while protecting your identity.)

- What gender do you most strongly identify with?

○ Male

- Female

- Here, female-identified participants completed the Male Role Norms Inventory and the Feminine Gender Role Stress Scale.

- What is your age?

- $\quad$ At Time 1 only] Please indicate your class standing below.

- Undergraduate freshman

○ Sophomore

- Junior

- Senior

- Graduate student

○ Non-degree seeking student

- What is your major?

○ Psychology

- Women's Studies

- Other (please describe)

- Are you taking this class for credit in a University Studies cluster?

- Yes

○ No

- Undecided

- $\quad$ At Time 1 only] How many classes did you miss this quarter?

- None

○ $1-2$

○ $3-4$

○ 5 or more

- $\quad$ At Time 2 only] How would you describe your race?

- White/Caucasian

- Black/African American

- Latino/Hispanic

- Asian or Pacific Islander

- Native American

- Other (please describe below)

- How would you describe your sexual orientation?

- Straight/heterosexual

$\circ$ Bisexual 
- Gay/homosexual

O Other (please describe)

- Please indicate your relationship status.

- Single (never married)

- In a casual relationship

- In a serious relationship

- Married or in a domestic partnership

- Divorced or separated

- Over the past 10 weeks, how often did you think about gender roles (their characteristics or implications)?

○ Never

- About once per month

- A few times per month

- A few times per week

○ Daily

- More than once per day

- Over the past 10 weeks, how often did you talk about gender roles with others?

o Never

- About once per month

A few times per month

- A few times per week

- Daily

- More than once per day

- Time 1 Debriefing Form (Appendix C) or Time 2 Debriefing Form (Appendix D) 


\section{Appendix C \\ Time 1 Debriefing Form \\ PORTLAND STATE UNIVERSITY \\ Department of Psychology}

\section{Debriefing Form \\ "Psychology of Men and Masculinity" Course Evaluation}

Thank you for your participation in this study! We truly appreciate the time and energy you have invested. At the end of the quarter, you will have an opportunity to complete this survey again. After the data have been analyzed, Prof. Mankowski will email you with the results for your class. Please remember: your answers are confidential, and all data is stored on PSU's secure network.

If anything in the study made you feel uncomfortable or brought up distressing experiences, please don't hesitate to contact Student Health and Counseling at 503.725.2800 or one of the researchers listed below. You may also wish to contact the National Sexual Assault Hotline at 1-800-656-HOPE or find a local crisis counseling center (http://centers.rainn.org/).

You are also welcome to contact any of the people at the bottom of this page with comments, questions, or concerns. Upon completion of the follow-up study at the end of the quarter, we will provide you with a detailed explanation of the background for our study and our hypotheses regarding the results.

Your contribution is invaluable!

Contact Information:

Professor Eric Mankowski, Principal Researcher: mankowskie@pdx.edu Sylvia Kidder, Researcher: sylvia2@pdx.edu 


\section{Appendix D}

Time 2 Debriefing Form

\section{PORTLAND STATE UNIVERSITY Department of Psychology}

\section{Debriefing Form \\ "Psychology of Men and Masculinity" Course Evaluation}

Thank you for your participation! We hope your exposure to the gender role beliefs scales was educational and enhanced your understanding of the course material. The purpose of this study was twofold: to continue Prof. Eric Mankowski's investigation of the changes in gender role beliefs resulting from this course's completion, and to discover if decreases in the endorsement of traditional gender role norms correlates with increased sexual satisfaction. There have been few studies assessing the educational and practical outcomes of gender-related courses, and you have provided a valuable contribution to this budding area of psychology.

An additional area of interest was whether changes in gender role beliefs correlates with increased sexual satisfaction (in other words, whether people with more progressive attitudes about men's and women's societal roles have more satisfying sex lives). Sexual satisfaction is important in many areas of life including overall health, quality of life, and relationship satisfaction (Apt, Hurblert, Pierce, \& White, 1996; Davison, Bell, LaChina, Holden, \& Davis, 2009; Rosen \& Bachmann, 2008). However, sexual satisfaction itself is influenced by interrelated social factors such as the beliefs one holds regarding the proper social roles of women and men (Klimicka, Cross, \& Tarnai, 1983; Rosenzweig \& Dailey, 1989; Sanchez, Crocker, \& Boike, 2005). If we find evidence that teaching students to think critically about gender roles (in this case, masculinity) increases sexual satisfaction, it will have implications in the areas of public education and counseling.

As part of this experiment, you completed questionnaires assessing your gender role beliefs (men took the Gender Role Conflict Scale; women took the Male Role Norms Inventory and Feminine Gender Role Stress Scale) and your sexual satisfaction (using the New Sexual Satisfaction Inventory), depending on your age and reported sexual experiences. All of these questionnaires are available through the references listed below.

If anything in the study made you feel uncomfortable or brought up distressing experiences, please don't hesitate to contact Student Health and Counseling at 503.725 .2800 or one of the researchers listed below. You may also wish to contact the National Sexual Assault Hotline at 1-800-656-HOPE or find a local crisis counseling center (http://centers.rainn.org/). 
Again, your responses are anonymous and cannot be tied to you personally. We understand the sensitive nature of some of the questions you answered, and we truly appreciate your honest responses. If you would like to learn more about this study or to offer your comments, you can contact one of the researchers listed below. We will email you the results for your class soon.

Contact Information:

Professor Eric Mankowski, Principal Researcher: mankowskie@pdx.edu

Sylvia Kidder, Researcher: sylvia2@pdx.edu

References:

Apt, C., Hurlbert, D. F., Pierce, A. P., \& White, L. C. (1996). Relationship satisfaction, sexual characteristics and the psychosocial well-being of women. The Canadian Journal of Human Sexuality, 5, 195-210.

Belk, S. S., \& Snell, W. E. (1986). Beliefs about women: Components and correlates. Personality and Psychology Bulletin, 12, 403-413.

Gillespie, B. L., \& Eisler, R. M. (1992). Development of the Feminine Gender Role Stress Scale: A cognitive-behavioral measure of stress, appraisal, and coping for women. Behavior Modification, 16, 426-438. doi:10.1177/01454455920163008

Kimlicka, T., Cross, H., \& Tarnai, J. (1983). A comparison of androgynous, feminine, masculine, and undifferentiated women on self-esteem, body satisfaction, and sexual satisfaction. Psychology of Women Quarterly, 7, 291-294.

Levant, R. F., Hirsch, L., Celentano, E., Cozza, T., Hill, S., MacEachern, M. (1992). The male role: An investigation of norms and stereotypes. Journal of Mental Health Counseling, 14, 325-337.

Mahalik, J. R., Morray, E. B., Coonerty-Femiano, A., Ludlow, L. H., Slattery, S. M., \& Smiler, A. (2005). Development of the Conformity to Feminine Role Norms Inventory. Sex Roles, 52, 417-435. doi:10.1007/s11199-005-3709-7

Nelson, M. C. (1988). Reliability, validity, and cross-cultural comparisons for the simplified Attitudes Toward Women Scale. Sex Roles, 18, 289-296.

O’Neil, J. M. (1986). Gender-role Conflict Scale: College men's fear of femininity. Sex Roles, 14, 335-350.

Rosen, R., Brown, C., Heiman, J., Leiblum, S., Meston, C., Shabsigh, R., Ferguson, D., \& D'Agostino, Jr., R. (2000). The Female Sexual Function Index (FSFI): A multidimensional self-report instrument for the assessment of female sexual function. Journal of Sex \& Marital Therapy, 26, 191-208.

Rosenzweig, J. M., \& Dailey, D. M. (1989). Dyadic adjustment/sexual satisfaction in women and men as a function of psychological sex role self-perception. Journal of Sex \& Marital Therapy, 15, 42-56.

Sanchez, D. T., Crocker, J., \& Boike, K. R. (2005). Doing gender in the bedroom: Investing in gender norms and the sexual experience. Personality and Social Psychology Bulletin, 31, 4445-1455. doi:10.1177/0146167205277333 
Stulhofer, A., Busko, V., \& Brouillard, P. (2010). Development and bicultural validation of the New Sexual Satisfaction Scale. Journal of Sex Research, 47, 257-268. doi:10.1080/00224490903100561 